\title{
Article \\ SUMOylation Potentiates ZIC Protein Activity to Influence Murine Neural Crest Cell Specification
}

\author{
Helen M. Bellchambers ${ }^{+} \mathbb{D}$, Kristen S. Barratt ${ }^{(D)}$, Koula E. M. Diamand $\mathbb{D}^{\mathbb{D}}$ and Ruth M. Arkell * \\ Early Mammalian Development Laboratory, John Curtin School of Medical Research, The Australian National \\ University, Canberra, ACT 2601, Australia; hbellcha@iu.edu (H.M.B.); kristen.barratt@anu.edu.au (K.S.B.); \\ koula.diamand@anu.edu.au (K.E.M.D.) \\ * Correspondence: ruth.arkell@anu.edu.au; Tel.: +61(0)-2-6125-9158 \\ † Present Address: Department of Pediatrics, Indiana University School of Medicine, \\ Indianapolis, IN 46202, USA.
}

Citation: Bellchambers, H.M.; Barratt, K.S.; Diamand, K.E.M.; Arkell, R.M. SUMOylation

Potentiates ZIC Protein Activity to Influence Murine Neural Crest Cell Specification. Int. J. Mol. Sci. 2021, 22, 10437. https://doi.org/10.3390/ ijms221910437

Academic Editor: Nicolas Pilon

Received: 3 September 2021

Accepted: 22 September 2021

Published: 28 September 2021

Publisher's Note: MDPI stays neutral with regard to jurisdictional claims in published maps and institutional affiliations.

Copyright: (c) 2021 by the authors. Licensee MDPI, Basel, Switzerland. This article is an open access article distributed under the terms and conditions of the Creative Commons Attribution (CC BY) license (https:// creativecommons.org/licenses/by/ $4.0 /)$.

\begin{abstract}
The mechanisms of neural crest cell induction and specification are highly conserved among vertebrate model organisms, but how similar these mechanisms are in mammalian neural crest cell formation remains open to question. The zinc finger of the cerebellum 1 (ZIC1) transcription factor is considered a core component of the vertebrate gene regulatory network that specifies neural crest fate at the neural plate border. In mouse embryos, however, Zic1 mutation does not cause neural crest defects. Instead, we and others have shown that murine Zic2 and Zic5 mutate to give a neural crest phenotype. Here, we extend this knowledge by demonstrating that murine Zic3 is also required for, and co-operates with, Zic2 and Zic5 during mammalian neural crest specification. At the murine neural plate border (a region of high canonical WNT activity) ZIC2, ZIC3, and ZIC5 function as transcription factors to jointly activate the Foxd3 specifier gene. This function is promoted by SUMOylation of the ZIC proteins at a conserved lysine immediately N-terminal of the ZIC zinc finger domain. In contrast, in the lateral regions of the neurectoderm (a region of low canonical WNT activity) basal ZIC proteins act as co-repressors of WNT/TCF-mediated transcription. Our work provides a mechanism by which mammalian neural crest specification is restricted to the neural plate border. Furthermore, given that WNT signaling and SUMOylation are also features of non-mammalian neural crest specification, it suggests that mammalian neural crest induction shares broad conservation, but altered molecular detail, with chicken, zebrafish, and Xenopus neural crest induction.
\end{abstract}

Keywords: TCF; Foxd3; post-translational modification; transcription factor; co-factor; ZIC; mouse neural crest cell

\section{Introduction}

Neural crest cells (NCCs) are a transient population of multipotent cells that arise at the border of the neural and non-neural ectoderm (known as the neural plate border) during neurulation. These cells undergo an epithelial-to-mesenchymal transition before migrating through the embryo, forming a diverse range of cell types such that the neural crest is often considered the fourth germ layer [1]. There is a general understanding of the signaling molecules and transcriptional cascade that drives neural crest specification; this is collectively called the neural crest gene regulatory network (GRN) [2-4]. Specifically, some of the major signaling pathways, including FGF, BMP, and WNT, act together to induce the expression of several genes, termed neural plate border genes. Though these genes collectively mark the neural plate border, their individual expression extends beyond this region. The neural plate border genes act in concert with the major signaling pathways to trigger expression of a second set of genes, termed the neural crest specifiers. These are the first markers of NCC fate and are believed to ultimately control NCC formation and behavior through regulating the expression of neural crest effector genes. 
Although the signaling cascade that directs neural crest specification is known, there is a lack of detailed understanding regarding the actions of specific molecules and transcription factors in directing neural crest development, particularly when comparing mammals to non-mammalian models [5]. For example, it is unclear if canonical WNT signaling plays the same role in the mouse as it does in the other model organisms used to study neural crest formation. Knockout or knockdown of canonical WNT ligands causes impaired neural crest induction phenotypes in Xenopus, chick, and zebrafish [6-12] but this phenotype is not replicated when the same genes are knocked out in the mouse [5,13-18]. Barriga et al. proposed several technical explanations for this difference including that (1) the wingless/integrated 1(Wnt1)-Cre line typically used to study neural crest in mice may not be targeting the earliest stages of neural crest formation and (2) there may be redundancy or compensation from other WNT ligands. In fact, ectopic activation of canonical WNT signaling in the anterior of the mouse embryo via knockout of the WNT antagonist dickkopf-related protein 1 (Dkk1) [19], or conditional inactivation of the WNT transcriptional repressor transcription factor 7 like 1 (Tcf7l1) [20], induces ectopic neural crest induction, suggesting canonical WNT signaling is still part of the mammalian neural crest GRN.

There is growing evidence that non-mammalian neural crest specification and differentiation is regulated by the post-translational modification SUMOylation. SUMOylation is the attachment of the SUMO (small ubiquitin-like modifier) protein to target proteins via an enzymatic cascade involving a dimeric E1 activating enzyme, a single E2 conjugating enzyme UBC9 (also known as UBE2I), and a limited number of E3 ligating enzymes. In the chick embryo, UBC9 is enriched in the neural folds where the future NCCs are located, and morpholino knockdown of UBC9 reduces the expression of several neural crest specifiers (including SNAIL2, SOX9, and FOXD3) without altering expression of neural plate border genes [21]. In chick and Xenopus embryos, the SUMOylation of neural plate border and specifier transcription factors such as PAX7, SOX9/Sox9, and SOX10/Sox10 is critical for NCC development [21-24]. Together this suggests an overarching role for SUMOylation for the regulation of neural crest.

We have recently shown that another protein associated with neural crest, ZIC5, is also regulated by SUMOylation [25]. ZIC5 is a member of the ZIC (zinc finger of the cerebellum) gene family that encodes multifunctional transcriptional regulators. In several species, including Xenopus and chick, a different member of the ZIC family, Zic1, is known to be a neural plate border gene. In Xenopus, Zic1 is believed to be of critical importance for formation of the neural crest, as co-expression of Zic1 with Pax3, another neural plate border gene, is sufficient to activate expression of neural crest specifiers including Snail and Foxd3 [26-28] and to cause an epithelial-to-mesenchymal transition in Xenopus ectoderm explants [26]. In chick, expression of ZIC1 has been found to be critical for activation of a FOXD3 enhancer that drives trunk neural crest specification [29]. In mice, however, Zic1 expression is not detected during the time of NCC induction [30] and deletion of murine Zic1 does not lead to a neural crest phenotype (reviewed in [31]). Other members of the murine ZIC family (Zic2, Zic3, and Zic5) are expressed in the neurectoderm during gastrulation and neurulation, including in the neural plate border region that is the site of neural crest specification [30,32,33]. Loss-of-function mutations in either Zic2 or Zic5 result in the depletion of NCCs and lead to neural crest-related phenotypes including ventral spotting and reduced cephalic neural crest tissues [25,34-38], suggesting the other Zic genes have acquired the role of neural plate border genes from Zic1 in mammalian species.

The defining feature of the ZICs is a zinc finger domain, closely related to the zinc finger domains of the GLI, GLIS, and NKL protein families [34]. The zinc finger domain is thought to have several functions including interacting with DNA [39,40], interacting with proteins [41,42], and possibly localizing ZICs to the nucleus [43,44]. One of the functions of the zinc finger domain is to enable the ZICs to bind TCF proteins, the key transcriptional mediators of canonical WNT signaling. TCF proteins bind DNA, with the TCF binding site referred to as a WNT-response element (WRE). In the absence of WNT ligand, the $\beta$-catenin 
molecule is degraded in the cytoplasm, causing TCF proteins to complex in the nucleus with other transcription factors to repress transcription at WREs. When WNT ligand is present, cytoplasmic $\beta$-catenin is stabilized and enters the nucleus where it complexes with TCF proteins and activates transcription at WREs [45]. The ZIC proteins bind TCF proteins and function as a co-repressor to block transcription at WREs when overexpressed in human cells or Xenopus and zebrafish embryos [42,46,47].

Outside the zinc finger domain, the ZICs are more varied, but all vertebrate ZICs share the zinc finger $\mathrm{N}$-terminally conserved (ZF-NC) domain, a small domain (14-21 amino acids) that is located immediately adjacent to the zinc finger domain [48]. The function of the ZF-NC is unknown; however, we recently showed it contains a highly conserved SUMOylation consensus sequence that is targeted for SUMOylation in response to canonical WNT signaling in ZIC5 [25]. Here, we further investigated the connection between WNT signaling, ZIC function, and SUMOylation during mammalian NCC induction and specification. Using cell-based assays, we found that ZIC proteins 1-4 are SUMOylated at a lysine within the highly conserved ZF-NC domain. Via a combination of compound mouse mutants and cell-based assays, we showed that the three neural plate border-expressed Zic genes (Zic2, Zic3 and Zic5) act co-operatively to drive the expression of the Foxd3 specifier gene, and that SUMOylation enhances ZIC2 and ZIC3s trans-activation at a Foxd3 enhancer element. In contrast, SUMOylation decreases ZIC2 and ZIC3s TCF co-repressor activity, and we found that the previously demonstrated ability of the ZIC proteins to inhibit WNTdependent TCF-mediated transcription varies with the level of WNT stimulation. In the presence of a medium level of WNT stimulation, each ZIC protein inhibits TCF-mediated transcription, but this ability is impaired or lost when WNT signaling activity is high. In the mouse embryo, a TCF-dependent GFP reporter indicates that canonical WNT-dependent transcription is active in a subset of cells within the dorsal neurectoderm at the time of murine NCC specification. The loss of Zic3 function leads to an increase in the size of the TCF-dependent transcription domain in the neurectoderm, indicating that during normal development ZIC represses TCF-mediated transcription in this tissue. Additionally, we found that the proportion of SUMOylated ZIC protein increases in response to high levels of WNT signaling. Together the data suggest that ZIC proteins play multiple roles within the neurectoderm at the time of NCC specification. In the lateral neurectoderm (where WNT levels are relatively low), they repress TCF-dependent transcription. At the neural plate border, in the presence of high WNT signals, SUMOylation of ZIC protein shifts ZIC activity from TCF co-repressor at WREs to a transcriptional activator of ZREs, including those that control Foxd3 expression. Considering these results, we propose a model in which canonical WNT signaling changes the activity of ZIC protein at the neural plate border to cause localized NCC specification.

\section{Results}

\subsection{The ZIC Proteins Can Be SUMOylated at a Conserved Lysine in the ZF-NC Domain}

During murine NCC formation, ZIC5 regulation of Foxd3 expression requires posttranslational modification of the ZIC5 protein by SUMOylation at a lysine within the highly conserved ZF-NC domain [25]. The paralogous ZIC3 lysine is also a SUMO substrate [49], and a high-throughput proteomic study [50] and search for high-probability consensus SUMOylation motifs within the ZIC proteins $[25,51]$ suggest all human ZIC proteins can be SUMOylated. To determine if this is the case, the various ZICs were assessed using the UBC9 fusion-directed SUMOylation (UFDS) system. In this system the potential target protein and UBC9 are expressed as a fusion protein, thereby removing the need for SUMO ligases $[52,53]$. To utilize this system, HEK293T cells were transiently transfected with a UBC9-fused version of the V5 epitope-tagged wild-type human ZIC1-4 (V5-UBC9ZIC1-WT, etc.) alone or with either emerald green fluorescent protein (EmGFP)-tagged wild-type SUMO1 (EmGFP-SUMO1-WT) or a SUMOylation-defective SUMO1 mutant (EmGFP-SUMO1- $\Delta$ GG) [54]. Attachment of EmGFP-SUMO1-WT should increase the molecular mass of target proteins by approximately $40 \mathrm{kDa}$; thus, the cells were lysed and 
subjected to SDS-PAGE and western blotting (WB) to assess the protein size. As shown in Supplementary Figure S1a-d, in each case, additional heavier, ZIC-specific bands were detected in addition to the unmodified ZIC band only in the presence of wild-type SUMO1 protein, indicating that ZIC1, ZIC2, ZIC3, and ZIC4 can be SUMOylated. The UBC9 fusion could force the post-translational modification of a protein not normally SUMOylated. To exclude this possibility, the transfections were repeated using ZIC proteins without the UBC9 fusion (i.e., with V5 epitope-tagged ZIC). As before, higher-molecular-mass bands were observed only in the presence of EmGFP-tagged SUMO1, indicating all members of the ZIC family were SUMOylated (Supplementary Figure S1e-h). In each case, the molecular mass of the ZIC protein increased by more than $40 \mathrm{kDa}$, which is consistent with the attachment of multiple EmGFP-tagged SUMO1 molecules.

SUMOylation generally modifies a lysine within a motif of conserved residues (YKXE), enabling the identification of high-probability SUMO sites via sequence analysis. In addition to the highly conserved SUMOylation site in the ZF-NC domain within ZIC1-4, our previous analysis showed that human ZIC1 and ZIC3 also contain a second high-probability canonical SUMOylation site at the boundary of zinc fingers 3 and 4 [25] (Figure 1a). To determine which of the predicted SUMOylation sites within ZIC1-4 are bona fide sites of SUMO attachment in HEK293T cells, each putative, modified lysine (K) was converted to an arginine (R) (which cannot be modified be SUMOylation) in the V5 epitope-tagged mammalian expression construct. Each construct was then transiently transfected into HEK293T cells in the presence or absence of EmGFP-SUMO1-WT before the cells were lysed and the resulting ZIC protein forms were analyzed by SDS-PAGE and WB. As shown in Figure 1b-e, for each ZIC protein, substitution of the ZF-NC lysine (i.e., ZIC1-K222R, ZIC2K253R, ZIC3-K248R, and ZIC4-K125R) was sufficient to prevent all SUMO conjugation. In contrast, substitution of the lysine at the boundary of zinc fingers 3 and 4 (ZIC1-K333R of ZIC3-K359R) did not alter the ZICs' SUMOylation status relative to the wild-type forms of these proteins. Even when the pool of SUMOylated ZIC was specifically increased by UBC9 fusion (using the UFDS system), only mutation of the ZF-NC lysine caused significant loss of the relevant-sized products (Supplementary Figure S2a-d, $\mathrm{a}^{\prime}-\mathrm{d}^{\prime}$ ). The data indicate that, in HEK293T cells, each ZIC protein is poly-SUMOylated at a canonical SUMOylation site within the ZIC ZF-NC domain. 
a
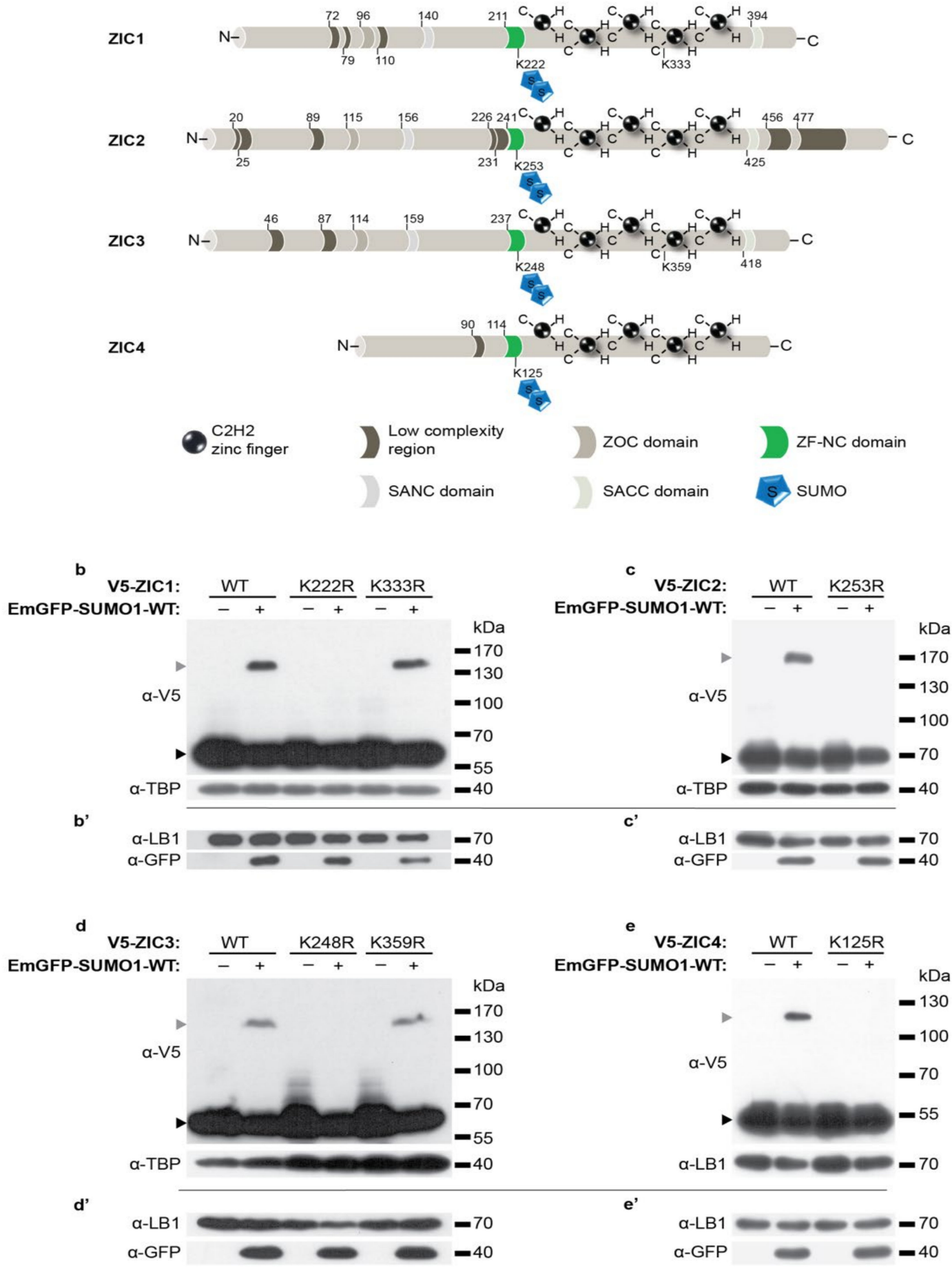

Figure 1. ZIC proteins are SUMOylated within the ZF-NC domain. (a) Schematic of human ZIC1-4 showing the SUMO attachment site. (b,c,d,e) Representative WBs of HEK293T cell nuclear fractions following transfection with the V5 epitopetagged ZIC expression plasmid shown, with or without EmGFP-tagged SUMO1-WT expression construct. (b) ZIC1, (c) ZIC2, (d) ZIC3, and (e) ZIC4. The SUMO-dependent higher-molecular-mass form of each protein is not produced when the putative target lysine (K) within the ZF-NC (ZIC1 K222, ZIC2 K253, ZIC3 K248, and ZIC4 K125) is changed to an arginine (R), indicating these are the sole site of SUMO attachment in each protein. The higher-molecular-mass protein is produced when the other putative target lysines are altered (ZIC1 K333 and ZIC3 K359), indicating that these lysines are not a SUMO target. Gray arrow, SUMOylated ZIC; black arrow, basal ZIC. $\left(\mathbf{b}^{\prime}, \mathbf{c}^{\prime}, \mathbf{d}^{\prime}, \mathbf{e}^{\prime}\right)$ WB to show overexpressed EmGFP-SUMO1-WT protein and corresponding loading control. For each protein, $n=3$ independent transfections and WB. For WB of nuclear fractions (using antibodies against V5 or GFP), antibody against TBP or Lamin B1 (LB1) was used as a loading control, respectively. 


\subsection{The Zic Genes Cooperate during Murine Neural Crest Cell Specification}

To determine if, as for murine ZIC5 [25], SUMOylation potentiates ZIC transcription factor activity during NCC formation, we first identified those ZIC family members that are required for this process. During murine embryogenesis, three Zic genes (Zic2, Zic3, and Zic5) are expressed in the gastrula ectoderm fated to give rise to the neural crest and at the neural plate border [30,32]. In contrast, Zic1 and Zic4 are not expressed during gastrulation and early neurulation [30,34]. Neural crest defects have been reported in murine embryos with severe loss-of-function mutations in Zic2 [36] or Zic5 [38]. In each case, neural crest specification is impaired, resulting in decreased (but not absent) formation of NCCs. To determine whether Zic2, 3, and 5 may act redundantly at the neural plate border, the expression of the Foxd3 specifier gene, a direct target of ZIC1 during chick NCC specification [29], was examined in murine embryos with decreased Zic gene dosage (Figure 2). Reduction of Zic gene dosage was achieved using the previously described null mouse strains: $\mathrm{Zic}^{\mathrm{Ku}}$ [36], Zic3 ${ }^{\mathrm{Ka}}[55,56]$, and Zic5 ${ }^{-}[25,38]$. Consistent with previous studies, embryos homozygous for these alleles of Zic2 or Zic5 alone showed depletion of Foxd3 expression in pre-migratory cranial and trunk neural crest (Figure 2a,b,d) relative to their stage-matched, wild-type littermates [25,35,36]. Similarly, embryos deficient in Zic3 alone showed depletion of Foxd3 (Figure 2a,c) demonstrating that all three of the murine Zic genes expressed at the neural plate border play a role in NCC specification and the control of Foxd3 expression. To further reduce Zic gene dosage, the single mutant strains were crossbred. Compound alteration of Zic2/Zic5 gene dosage is not possible by crossbreeding due to their bi-gene arrangement [34]; instead, Zic3 and either Zic2 or Zic5 compound heterozygous mutants were generated. As shown in Figure 2a,e,f, cranial neural crest specification showed a greater dependence on Zic3 and Zic5 gene function. Comparatively, when embryos that lack Zic3 and have only one functioning copy of either Zic2 or Zic5 were generated, there was a substantial depletion (or complete loss) of Foxd3 trunk expression and very little cranial Foxd3 expression was retained (Figure 2a,g,h). Together the data indicate Zic2, Zic3, and Zic5 act redundantly at the murine neural plate border to direct expression of Foxd3. 

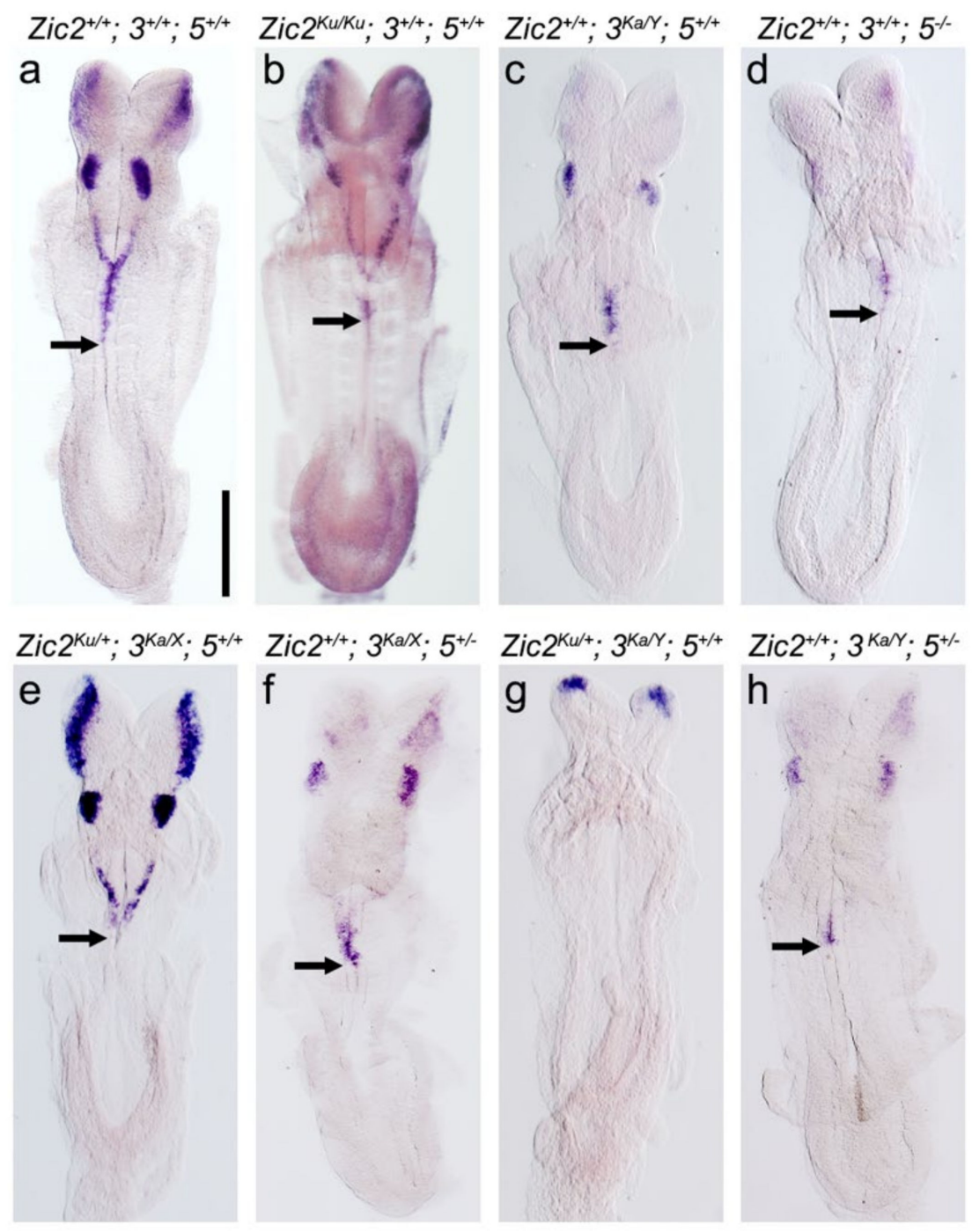

Figure 2. The Zic genes co-operate during murine neural crest cell specification. (a-h) Dorsal view of 8-somite stage murine embryos of the genotypes shown, following WMISH to Foxd3 (anterior to the top). The black arrow marks the distal extent of Foxd3 expression. The genotype is shown at the top of each panel and is abbreviated such that the Zic gene symbol is shown only once per panel. The murine Zic genes are located as follows (assembly GRCm39) Zic5-Mmu 14: (122696572..122703127, complement), Zic2-MMu 14: (122712796..122717740), and Zic3-MMu X: (57075988..57081990) and would normally be in chromosome order in a compound genotype. Instead, they are written in numerical order for ease of reading (i.e., in panel a, the genotype $\mathrm{Zic}^{+/+} ; 3^{+/+} ; 5^{+/+}$is used to represent $\mathrm{Zic5}^{+/+} ; \mathrm{Zic2}^{+/+} ; \mathrm{Zic3}^{+/+}$). Scale, $200 \mu \mathrm{m}$.

\subsection{SUMOylation Promotes ZIC Trans-Activation of the Foxd3 Enhancer}

Having confirmed ZIC2, ZIC3, and ZIC5 cooperate to promote neural crest development, cell-based assays were employed to assess how SUMO modification of these proteins affects this ability. To evaluate ZIC regulation of Foxd3, a luciferase reporter construct containing the murine genomic region equivalent to the previously identified ZIC-responsive chick FOXD3 enhancer $[25,29,57]$ was used. We previously demonstrated that ZIC trans-activation of this reporter construct requires ZIC DNA binding [25]; thus, ZIC proteins act as classical transcription factors at this element. The ability of basal versus SUMOylated ZIC proteins to stimulate reporter expression was quantified. Two methods were used to prevent SUMOylation of the exogenous ZIC proteins. First, to specifically inhibit ZIC SUMOylation we employed the V5 epitope-tagged ZIC expression constructs in which the ZF-NC target lysine had been converted to a non-modifiable arginine or, second, 
SUMOylation was universally inhibited via the co-expression of a dominant-negative UBC9 molecule (Flag-UBC9-C93S; [58]). As shown in Figure 3a,c, both ZIC2 and ZIC3 require SUMOylation for maximal activity at the Foxd3 ZIC-responsive enhancer, since arginine substitution at the ZF-NC target lysine reduces reporter trans-activation. Moreover, in the presence of universal SUMO inhibition, the trans-activation activity of the wild-type ZIC2 or ZIC3 protein is reduced to that of the respective SUMO-incompetent form (ZIC2-K253R and ZIC3-K248R) (Figure 3b,d). This suggests that, as for the ZIC5 protein [25], SUMOylation promotes the ZIC-based trans-activation of the Foxd3 reporter construct. Conversely, the SUMO-incompetent forms of ZIC1 and ZIC4 were as effective as their wild-type counterparts at trans-activation of the Foxd3 reporter construct when overexpressed in HEK293T cells (Supplementary Figure S3a, a', b, b').

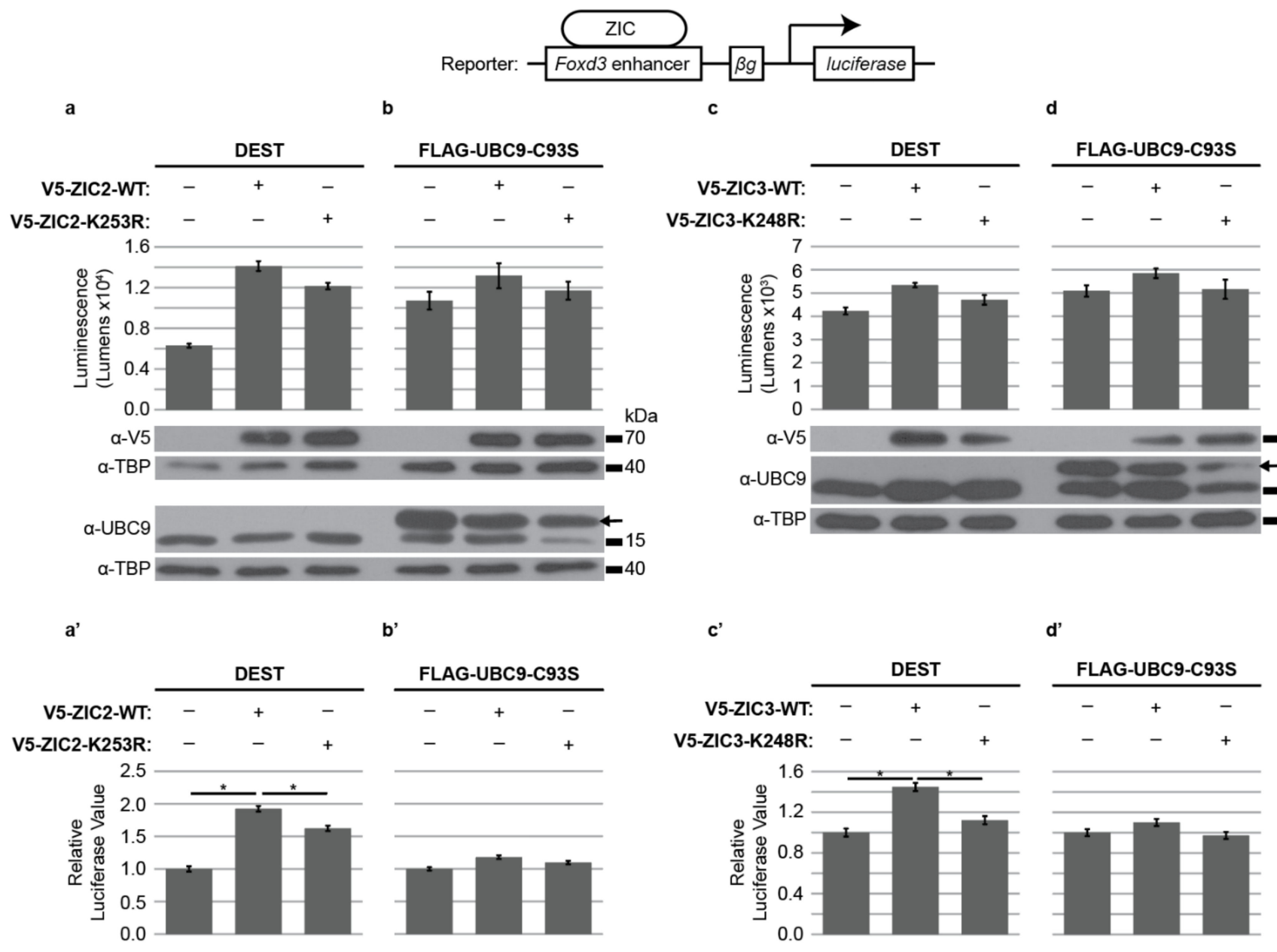

Figure 3. SUMOylation increases ZIC2 and ZIC3 transactivation of the Foxd3 enhancer. Luciferase activity at the Foxd3 reporter in HEK293T cells. (a,a') The K253R SUMO-incompetent form of ZIC2 shows a significant decrease in transactivation ability compared to wild-type ZIC2. (b, $\left.\mathbf{b}^{\prime}\right)$ The transactivation ability of wild-type ZIC2 is impeded when SUMOylation is universally inhibited via UBC9-C39S and is equivalent to the SUMO-incompetent form of ZIC2. (c,c') The K248R SUMOincompetent form of ZIC3 shows a significant decrease in transactivation ability compared to wild-type ZIC3. (d,d') The transactivation ability of wild-type ZIC3 is impeded when SUMOylation is universally inhibited via UBC9-C39S and is equivalent to the SUMO-incompetent form of ZIC3. (a-d) Raw data and WB showing overexpressed proteins from one representative experiment. For WB of nuclear fractions (using antibodies against V5 or UBC9) antibody against TBP was used as a loading control. The arrow in the UBC9 WB denotes the larger, tagged exogenous protein. In (a,b), the ZIC and UBC9 proteins were detected on separate blots, whereas in c and d all proteins were detected on one blot. Error bars denote \pm s.d. from three internal repeats. ( $\left.\mathbf{a}^{\prime}-\mathbf{d}^{\prime}\right)$ Pooled data from three external repeats (normalized to background). Error bars denote \pm s.e.m. *: $p<0.05$, two way ANOVA with Bonferroni multiple comparison test. 


\subsection{The ZIC Proteins Are Context-Dependent Inhibitors of Canonical WNT-Dependent Transcription In Vitro and In Vivo}

The activation of the Foxd3 enhancer provides one mechanism by which ZIC proteins can regulate neural crest specification. Several studies have, however, demonstrated that ZIC proteins can act as transcriptional inhibitors of canonical WNT signals $[42,46,47,56]$ via physical interaction with TCF proteins (which bind and repress or activate transcription at WREs). Given canonical WNT signaling can influence neural crest specification, such repression by the ZIC proteins could also influence specification of the neural crest. Thus, to further examine characteristics of this activity, a modified TOPflash/FOPflash vector system optimized for use with ZIC proteins was constructed. ZIC proteins are known to stimulate a variety of basal promoters widely used in heterologous reporter systems [40,56,59-61] including the TK promoter used in commercial TOPflash/FOPflash vectors. To circumvent this problem, new reporter constructs were generated (TOPflash equivalent: pGL4.20- $\beta$ globin-WREx3, and FOPflash equivalent with mutated WREs: pGL4.20- $\beta$-globin-MREx3) using a backbone, luciferase cDNA, and promoter ( $\beta$-globin), each of which has been independently tested and shown to be neutral with respect to exogenous ZIC protein activity in HEK293T cells [57]. Canonical WNT signaling is constrained in HEK293T cells and can be stimulated by transfection of a $\beta$-catenin expression plasmid, with transcription at TCF sites driven by endogenous TCF proteins. The level of WNT activity in this system can be titrated via the use of alternative forms of $\beta$-catenin, such as a truncated and, thus, stabilized form of $\beta$-catenin ( $\beta$-catenin- $\Delta$ N89 [62]), which drives higher luciferase activity (Supplementary Figure S4a). To measure the relative ability of all mammalian ZIC proteins to inhibit WNT-dependent transcription, each protein was co-transfected with the full-length form of $\beta$-catenin (V5- $\beta$-CAT) or the stabilized form $(\triangle \mathrm{N} 89-\beta-\mathrm{CAT})$ and luciferase activity of pGL4.2- $\beta$-globin-WREx3 quantified (Figure 4a,b,c). ZIC inhibition of TCF-dependent transcription was greatest in the presence of wild-type $\beta$-catenin, and, for each ZIC protein, transcription inhibition was decreased (ZIC1 and 2) or ablated (ZIC3, 4 , and 5 ) in the presence of $\beta$-catenin (Figure 2c). Luciferase transcription in these assays was dependent upon the presence of the TCF binding sites (i.e., the WRE) in the reporter construct since transcription was reduced to background levels when the binding sites were mutated (i.e., the MRE; Supplementary Figure S4b, $b^{\prime}$ ).

The results imply that, in HEK293T cells, ZIC proteins can inhibit TCF-dependent transcription at low levels of WNT activity, but that ZIC transcription inhibition is overcome when WNT activity increases. To test whether ZIC proteins influence TCF-dependent transcription in vivo, a WNT-reporter mouse strain (TCF/Lef:H2B-GFP; MGI: 4881498) was examined. This transgenic strain incorporates a human histone H2B-green fluorescent protein (GFP) fusion protein whose expression is driven by six repeats of the same WRE employed in the luciferase assays [63] followed by a hsp68 minimal promoter. In wild-type mouse embryos Zic2, 3, and 5 are all expressed throughout the neurectoderm but, beginning at the early somite stages, their transcripts disappear from the future ventral neurectoderm and become increasingly restricted to the future dorsal neurectoderm [34]. Thus, at the time of NCC specification the genes are expressed in a dorsal domain of the neurectoderm, which is broader than the crest-forming region. In wild-type embryos, the GFP reporter reveals WNT-dependent transcription restricted to the neural plate border, as expected. When crossed with mice null for Zic3, embryos that lack Zic3 function $\left(\mathrm{Zic} 3^{K a / Y}\right)$ showed an increase in the domain of GFP reporter activity in regions of normal Zic3 expression, including at the neural plate border and within the lateral neurectoderm at the time and site of neural crest cell specification (Figure $4 \mathrm{e}-\mathrm{h}$ ). This indicates that Zic expression is required for repression of TCF-dependent transcription in the lateral neurectoderm (but not neural plate border) and is consistent with the model from the cell-based studies, which implies that ZIC proteins are context-dependent inhibitors of canonical WNT/ $\beta$-catenin driven transcription. 

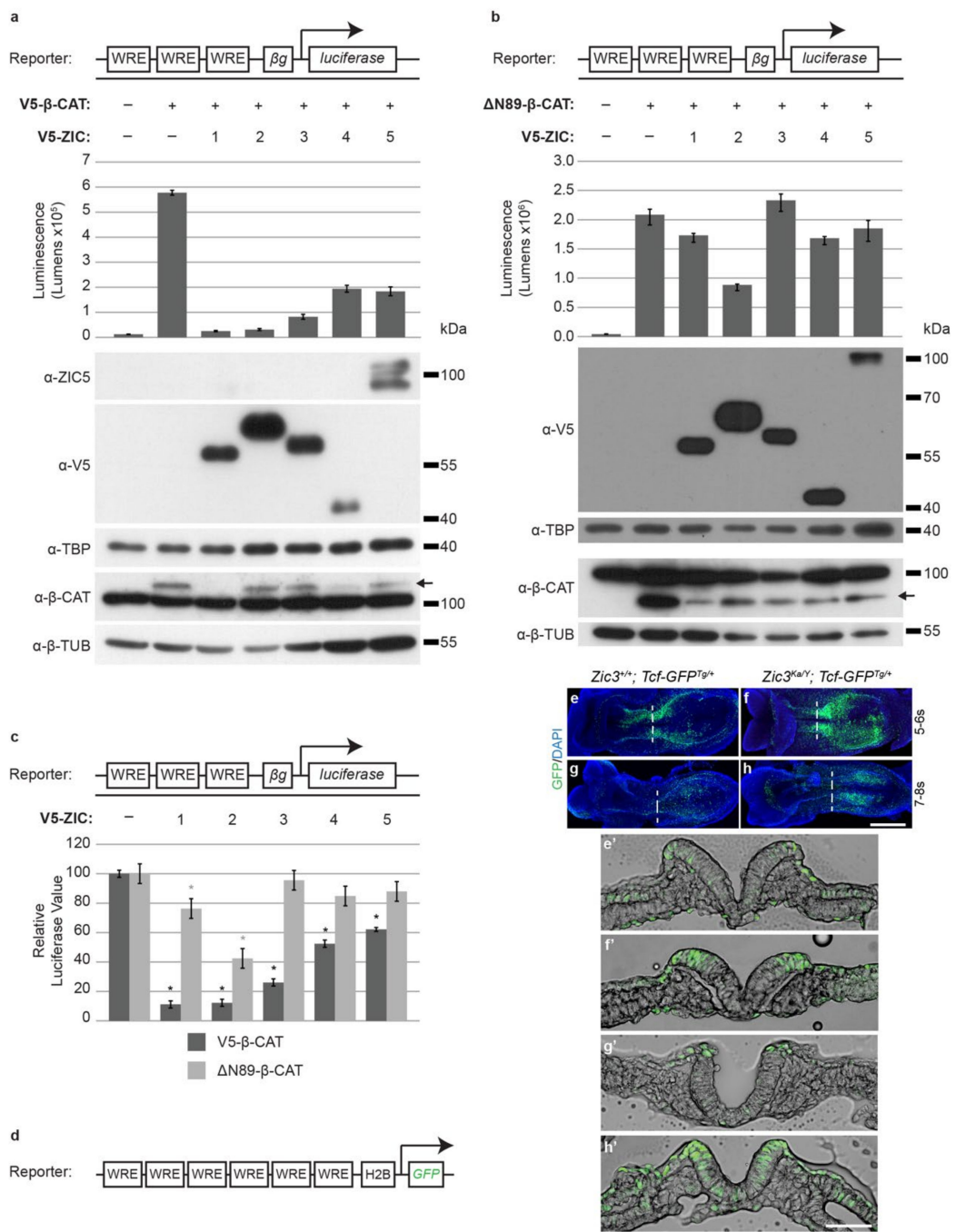

Figure 4. Context-dependent inhibition of $\mathrm{WNT} / \beta$-catenin-mediated transcription by the ZIC proteins. (a-c) Luciferase activity in HEK293T cells of the ZIC-optimized TCF-reporter construct shown driven by expression of epitope-tagged ZIC proteins (V5-ZIC1-5). WNT signaling was activated by transfection with (a) wild-type $\beta$-catenin (V5- $\beta$-CAT) or (b) stabilized $\beta$-catenin $(\Delta$ N89$\beta$-CAT) to give higher activity. $(\mathbf{a}, \mathbf{b})$ Raw data and corresponding WBs of the overexpressed proteins from one representative experiment. Error bars denote \pm s.d. of three internal repeats. For WB of nuclear fractions (using anti-V5 antibodies or anti-ZIC5-serum), antibodies against TBP were used as a loading control. For WB of cytoplasmic fractions (using anti- $\beta$-catenin antibody; $\alpha-\beta$-CAT) antibody against $\beta$-tubulin ( $\alpha$ - $\beta$-TUB) was used as a loading control. The arrow in the $\beta$-CAT WB denotes the larger, tagged exogenous protein. Exogenous $\beta$-CAT is depleted to varying extents in the presence of the different ZIC proteins, which is consistent with the observation that ZIC3 overexpression enhances $\beta$-catenin degradation $[46,56]$. (c) Pooled data from the experiments shown in $a$ and $b$ presented relative to the value given by the respective empty-vector control transfections. In each data set the relative luciferase value of the $\beta$-catenin transfection is set to $100 \%$. Error bars denote \pm s.e.m. of three external repeats, ${ }^{*}: p<0.05$, two-way ANOVA with Fischer's unprotected post ad hoc test. Black asterisk, V5- $\beta$-CAT data; gray asterisk, $\triangle$ N89- $\beta$-CAT data. Statistics to compare V5- $\beta$-CAT data and $\Delta$ N89- $\beta$-CAT data were not performed. (d) Line diagram of the TCF/Lef:H2BGFP mouse strain transgenic construct. $(\mathbf{e}, \mathbf{f}, \mathbf{g}, \mathbf{h})$ Dorsal view of wholemount embryos showing GFP (green) reporting TCF-mediated transcription and the DAPI (blue) nuclear stain. Scale, $200 \mu \mathrm{m}$. $\left(\mathbf{e}^{\prime}, \mathbf{f}^{\prime}, \mathbf{g}^{\prime}, \mathbf{h}^{\prime}\right)$ Transverse sections at levels shown in corresponding image of embryos, showing GFP (green) reporting TCF-mediated transcription and a bright-field image of the section. The embryos' genotype and stage are shown on each panel. Scale, $100 \mu \mathrm{m}$. 


\subsection{SUMOylation Decreases ZIC1, ZIC2, and ZIC3 Inhibition of TCF-Dependent Transcription}

We next evaluated how SUMOylation affects the ZIC modification of TCF-dependent transcription as measured by the ZIC-optimized WRE-reporter system in HEK293T cells. To take account of the different dose-dependent inhibitory abilities of ZIC2 and ZIC3 (see Figure 4), different $\beta$-catenin expression constructs were used to stimulate TCF-dependent transcription for different ZIC proteins. The role of SUMOylation was evaluated both by specific inhibition of ZIC SUMOylation through expression of SUMO-incompetent ZIC proteins (V5-ZIC2-K253R or V5-ZIC3-K248R) or universally by co-expression of FlagUBC9-C93S with V5-ZIC2-WT or V5-ZIC3-WT. For both ZIC2 and ZIC3, overexpression of the SUMO-incompetent forms significantly enhanced suppression of TCF-dependent transcription, relative to the respective wild-type protein (Figure $5 a, a^{\prime}, c, c^{\prime}$ ). Furthermore, the presence of dominant-negative UBC9 converted wild-type ZIC2 or ZIC3 into a stronger inhibitor of TCF-dependent transcription (Figure $5 b, b^{\prime}, d, d^{\prime}$ ), indicating that SUMOylation of the ZF-NC lysine accounts for the increased inhibitory activity of the K-R ZIC variant proteins. When the non-neural plate border ZIC proteins were assayed in this manner, it was found that SUMOylation of ZIC1 similarly enhanced its capacity to inhibit TCFdependent transcription, but that SUMOylation did not alter ZIC4 suppression activity (Supplementary Figure S5).

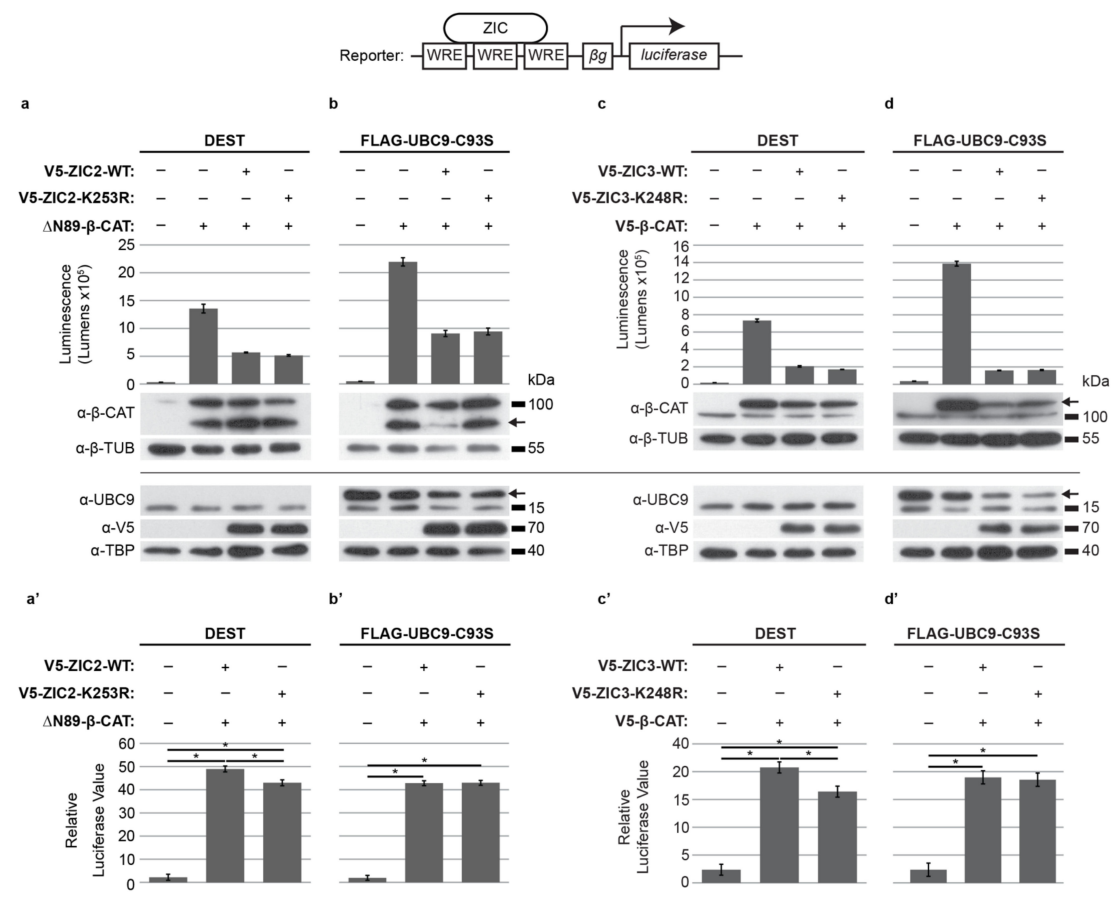

Figure 5. SUMOylation reduces ZIC inhibition of WNT signaling. Luciferase activity at the ZIC-optimized WRE reporter in HEK293T cells. (a,a') The K253R SUMO-incompetent form of ZIC2 shows a significant increase in inhibition of $\beta$-cateninmediated transcription compared to wild-type ZIC2. (b, $\left.\mathbf{b}^{\prime}\right)$ The ability of wild-type ZIC2 to inhibit $\beta$-catenin-mediated transcription is increased when SUMOylation is universally inhibited via UBC9-C39S and is equivalent to the SUMOincompetent form of ZIC2. (c, $\mathbf{c}^{\prime}$ ) The K248R SUMO-incompetent form of ZIC3 shows a significant increase in inhibition of $\beta$-catenin-mediated transcription compared to wild-type ZIC3. (d,d') The ability of wild-type ZIC3 to inhibit $\beta$-cateninmediated transcription is increased when SUMOylation is universally inhibited via UBC9-C39S and is equivalent to the SUMO-incompetent form of ZIC3. (a-d) Raw data and WB showing overexpressed proteins from one representative experiment. For WB of cytoplasmic fractions (using antibody against $\beta$-catenin; $\alpha$ - $\beta$-CAT), antibody against $\beta$-tubulin $(\alpha-\beta-$ TUB $)$ was used as a loading control. The arrow in the $\alpha$ - $\beta$-CAT WB $(\mathbf{a}-\mathbf{c})$ denotes the tagged exogenous protein (V5- $\beta$-CAT is larger and $\triangle \mathrm{N} 89-\beta$-CAT is smaller than the endogenous $\beta$-CAT). For WB of nuclear fractions (using antibodies against V5 or UBC9) antibody against TBP was used as a loading control. The arrow in the UBC9 WB denotes the larger, tagged exogenous protein. Error bars denote \pm s.d. from three internal repeats. $\left(\mathbf{a}^{\prime}-\mathbf{d}^{\prime}\right)$ Pooled data from three external repeats (normalized to background). Error bars denote \pm s.e.m. ${ }^{*}: p<0.05$, two-way ANOVA with Bonferroni multiple comparison test. 


\subsection{ZIC Protein SUMOylation Is Enhanced in a High-WNT Environment}

Murine NCC specification occurs at a region of high canonical WNT activity (see Figure $\left.4 \mathrm{e}, \mathrm{e}^{\prime}, \mathrm{g}, \mathrm{g}^{\prime}\right)$, and we previously showed that the proportion of SUMOylated ZIC5 protein increases in HEK293T cells following stimulation of WNT activity. This theoretically provides a mechanism to alter the balance of ZIC transcription factor versus co-factor activity within the neurectoderm dependent upon the level of canonical WNT activity at a given location. To determine whether the other ZIC proteins respond similarly to WNT activity, the proportion of SUMOylated ZIC protein was compared between HEK293T cells at basal state and following treatment with the potent GSK3 inhibitor $\left(2^{\prime} \mathrm{Z}, 3^{\prime} \mathrm{E}\right)$ 6-Bromoindirubin-3'-oxime (BIO) using a protocol known to stimulate canonical WNT signaling in HEK293T cells [64]. For this experiment we selected one neural plate border ZIC protein (ZIC2) and one non-neural plate border ZIC protein (ZIC1), to determine if they responded differentially. As shown in Figure $6 a-d$, the proportion of SUMOylated ZIC1 and ZIC2 protein is substantially increased following BIO treatment, indicating that canonical WNT signaling can regulate the post-translational modification of these proteins.
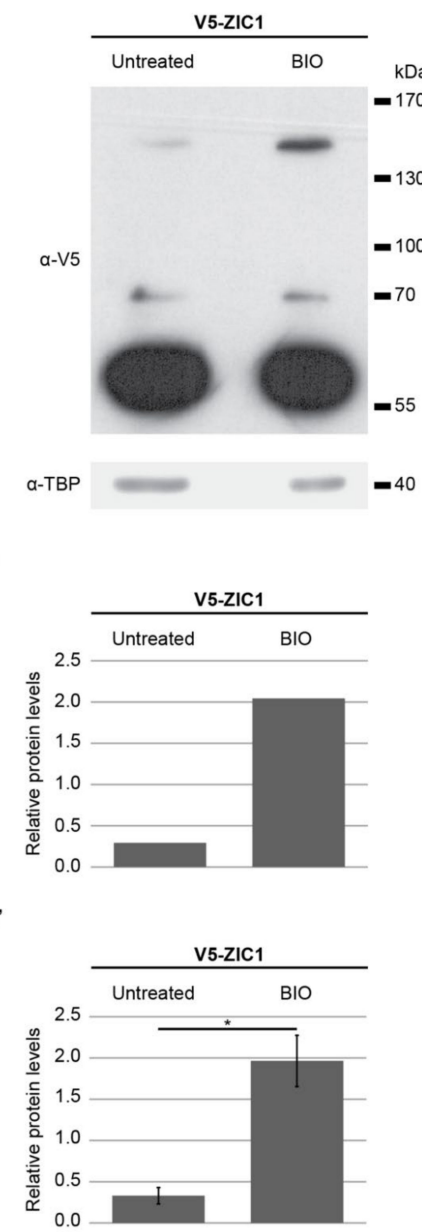
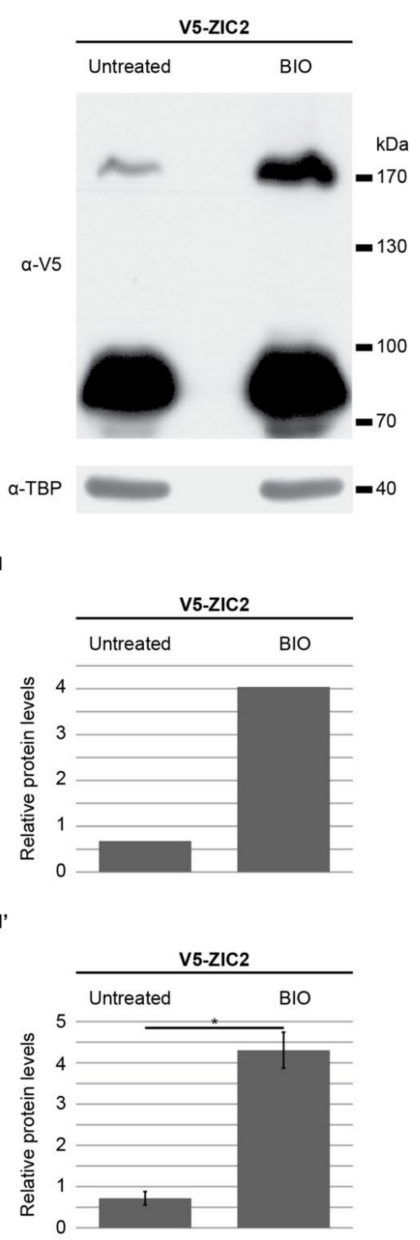

Figure 6. Activation of the canonical WNT pathway promotes ZIC SUMOylation. (a-d') Quantification of SUMOylated ZIC based on WB analysis of ZIC protein in the nuclear fraction of HEK293T cells co-transfected with V5 epitope-tagged ZIC expression plasmids and EmGFP-SUMO1-WT followed by incubation in the presence or absence of the GSK inhibitor (2'Z,3'E)-6-Bromoindirubin-3'-oxime (BIO). (a,b) Representative WBs for the ZIC1 or ZIC2 analysis. For WB of nuclear fractions (using antibody against V5), antibody against TBP was used as a loading control. (c,d) Quantification of the SUMOylated ZIC protein in the presence or absence of BIO in the WB shown in $(\mathbf{a}, \mathbf{b})$, respectively. ZIC1 and ZIC2 protein levels were quantified relative to TBP using ImageJ. $\left(\mathbf{c}^{\prime}, \mathbf{d}^{\prime}\right)$ Average level of SUMOylated ZIC protein from five independent experiments. For both ZIC1 and ZIC2, incubation with BIO significantly increases the amount of the SUMOylated form of ZIC. *: $p<0.01$ two-sample $t$-test. Error bars denote \pm s.e.m. 


\section{Discussion}

Here we demonstrated that, during normal development, murine ZIC proteins play two distinct roles during NCC specification. First, in the lateral neurectoderm (a region of relatively low WNT activity), ZIC3 (and potentially ZIC2 and ZIC5) acts at WREs to repress the expression of WNT target genes. Second, at the neural plate border (a region of high WNT activity and where WREs lead to gene transcription), ZIC proteins cooperate to drive the expression of the Foxd3 NCC specifier gene, likely via direct binding to and transactivation of ZREs. The ability of the ZIC proteins to switch from co-repressor at WREs to transcription factor at ZREs in a high-WNT environment can be facilitated by ZIC-protein SUMOylation, in response to the high level of WNT signaling. Together these data are synthesized into a working model of the role of ZIC proteins during NCC specification in Figure 7. In support of this model, we recently showed that ZIC5 SUMOylation is essential during murine development to drive optimal expression of Foxd3 and specification of the neural crest [25].

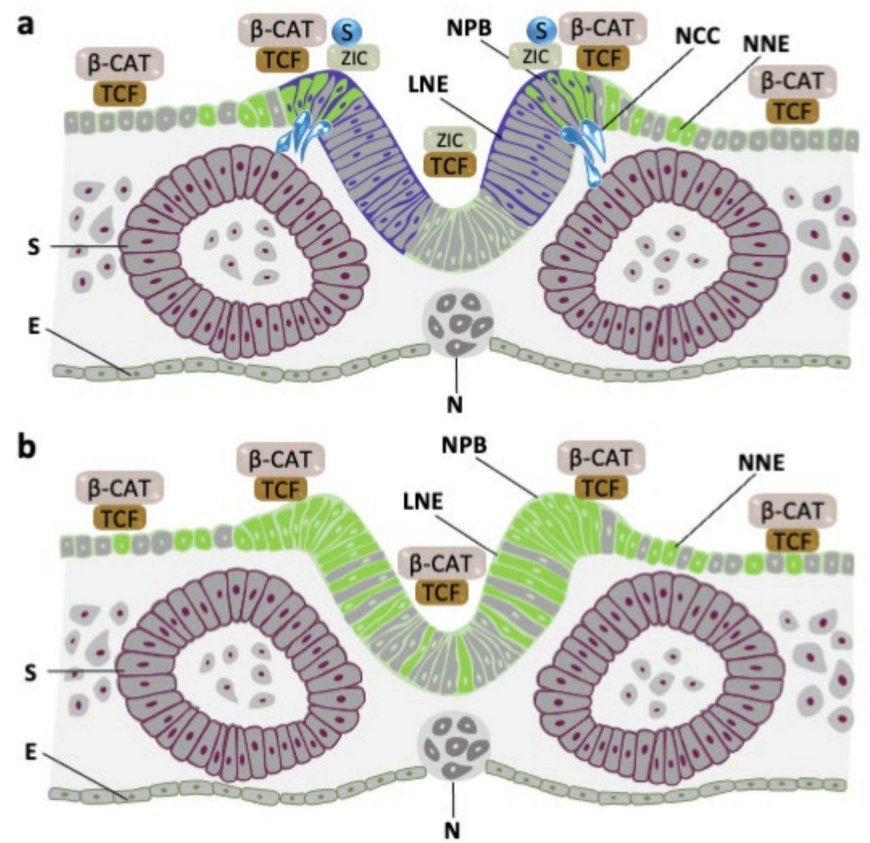

Figure 7. SUMOylation of ZIC proteins can influence NCC specification. A diagram explaining how ZIC protein activity at the neural plate border can restrict the region of NCC specification. (a) During normal development, WNT signaling sufficient to cause TCF activation of gene expression is restricted to the neural plate border and some non-neural ectoderm cells. Zic gene expression is within the lateral neurectoderm and neural plate border. In the lateral neurectoderm, basal ZIC acts as a TCF co-repressor. At the neural plate border, high-WNT activity promotes ZIC SUMOylation and transcription factor activity at ZREs, including those that drive expression of the Foxd3 specifier gene. (b) When Zic gene expression is depleted in the lateral neurectoderm, TCF activation of gene expression expands throughout the neurectoderm and into the non-neural ectoderm. Simultaneously, the lack of ZIC protein prevents activation of Foxd3 expression. E: endoderm, LNE: lateral neurectoderm, NCC: neural crest cells, NPB: neural plate border, NNE: non-neural ectoderm, N: notochord, S: somite.

We previously showed that Foxd3 expression during murine NCC specification requires Zic5 SUMOylation at a lysine within the deeply conserved ZF-NC protein domain [25]. We now show that each of the ZIC proteins can be polySUMOylated at the lysine within a high-probability SUMOylation consensus sequence in the ZF-NC domain and that this is the sole site of their SUMOylation. This confirms and extends the work of other 
studies suggesting ZIC proteins are a SUMO substrate [49,50] and supports the need for SUMOylation as a driver of the evolutionary conservation of the ZIC ZF-NC domain [25]. Furthermore, as for ZIC5, the steady-state level of ZIC1 and ZIC2 SUMOylation increases in the presence of high WNT activity. Although we have not directly tested ZIC3 and ZIC4 in this assay, it is possible that the SUMOylation of one, or both, of these proteins is also increased in a high-WNT environment. For the neural plate border Zic genes (Zic2, Zic3, and Zic5), our work here and in Ali et al., 2021, show that ZIC SUMOylation consistently correlates with decreased TCF co-repressor activity at WREs and increased trans-activation at the ZREs in the Foxd3 enhancer. As previously described, this SUMOylation-driven switch in ZIC function extends the reach of WNT signaling, enabling a high-WNT environment to activate transcription not only at WREs but also at ZREs [25], and it would be interesting to determine if other genes involved in neural crest specification are also regulated by this process. The work presented here also confirms that the well-described requirement for SUMOylation during NCC specification in chick and Xenopus embryos [21,22] is conserved in mammals. As with other features, however, the molecular details appear to have altered. For example, mRNA transcripts and protein levels of the SUMO E2 ligase UBC9, which is essential for SUMO conjugation, are enriched in the neural folds of chick where the future NCCs are located [21], whereas the same enrichment of SUMO pathway molecules is not seen in mouse embryos [65].

The work presented here confirms previous studies that indicate that the ZIC proteins contribute to transcription control downstream of WNT signaling. Several gain-of-function studies show that the ZIC proteins can directly bind TCF7L2 and, when co-expressed with TCF7L2, can inhibit TCF-dependent transcription at WREs $[42,46,47,56]$ in cells and in Xenopus and zebrafish embryos. Using a ZIC-optimized reporter assay in HEK293T cells, and various levels of WNT activation, we showed here that ZIC repression of WREs is overcome in high-WNT environments and that ZIC3, ZIC4, and ZIC5 are the most sensitive to this effect. Furthermore, we demonstrated for the first time that in vivo loss of ZIC activity (in murine Zic3 null embryos) leads to an increase in TCF-dependent transcription at WREs, confirming that ZIC co-repression at WREs is required for normal development. It would be interesting to conduct similar experiments with other murine Zic alleles to determine when and where during embryonic development the various ZIC proteins repress canonical WNT signaling. The work also showed that the WNT signaling pathway is active at the right time and place to be involved in the earliest steps of murine NCC development and that altered WNT activity is associated with a NCC phenotype. This supports a conserved requirement for WNT signaling in mammalian NCC formation and suggests there is merit in attempting new strategies to identify the relevant murine WNT ligands and pathway molecules.

Previous studies of the role of Zic genes at the neural plate border showed the importance of Zic1 in non-mammalian model organisms [26-29]. Here we showed that, during evolution, the role of ZIC in NCC specification has transferred and been split between multiple Zic genes, such that, in the mouse, Zic2, Zic3, and Zic5 together control NCC development. We showed these genes have adopted the function of activating Foxd 3 expression in the dorsal neurectoderm during NCC specification. We previously showed that ZIC5 can trans-activate an evolutionarily conserved enhancer sequence containing ZREs that was first identified in chick embryos [29] in a DNA binding-dependent manner [25]. Here we showed that both ZIC2 and ZIC3 trans-activate this enhancer element and that their SUMOylation enhances this ability. It remains possible that, in vivo, Foxd3 expression is activated by default in the dorsal neurectoderm where ZIC activity as a TCF co-repressor is lost due to high WNT signaling. Such a scenario would, however, be expected to lead to greater Foxd3 expression in the Zic3 null embryos due to the enlarged size of the TCFdependent expression domain. The finding of decreased Foxd3 expression in the dorsal neurectoderm of Zic3 null embryos argues that ZIC3 directly drives trans-activation of Foxd3 expression during NCC specification. Although it seems likely that the murine Zic genes would play a broader role in NCC specification by co-operatively regulating 
other genes at ZREs, we did not specifically test this here. Additionally, a more complete understanding of the cooperative role of the Zic genes is hindered by the mid-late-gestation lethality of Zic null alleles (which occurs at earlier embryonic stages in Zic compound mutants [66]) and the awaited development of additional mouse reagents such as conditional alleles of Zic2 and Zic5.

The balance between non-neural and neural fates is thought to be driven by WNT signaling levels [67]. SUMOylation of ZIC proteins in a high-WNT environment can explain how NCCs arise at a discrete region of the developing neurectoderm, despite a broader expression domain of the ZIC neural plate border transcription factors and active WNT signaling in the non-neural ectoderm. In regions of lateral neurectoderm, where WNT signaling is relatively low, the ZIC proteins predominantly act as TCF co-repressors at WREs and are not available to bind ZREs. At the neural plate border, high-WNT activity causes ZIC SUMOylation, preferencing their activity at ZREs and enabling TCF to complex with $\beta$-catenin and activate WREs. Further laterally still, in the non-neural ectoderm where ZIC proteins are not expressed, TCF/ $\beta$-catenin activity at WREs will occur, in the absence of ZIC binding to ZREs. It would be interesting to determine whether ZIC SUMOylation is used at other times and places during development to resolve WNT activity gradients.

\section{Materials and Methods}

\subsection{Mouse Strains and Husbandry}

Mice were maintained according to Australian Standards for Animal Care under protocol A2018/36 approved by The Australian National University Animal Ethics and Experimentation Committee for this study. The Zic5 ${ }^{\text {tm1Sia }}$ targeted null allele (MGI:3574814) of $\mathrm{Zic5}\left(\mathrm{Zic5} 5^{-}\right.$[38] was backcrossed for 10 generations to the $\mathrm{C} 3 \mathrm{H} / \mathrm{HeH}$ inbred strain and subsequently for $>10$ generations to the C57BL6/J inbred strain. The kumba $(K u)$ allele of $\mathrm{Zic2}[36,68]$ was maintained by continuous backcross to $\mathrm{C} 3 \mathrm{H} / \mathrm{HeH}$ mice. The katun $(\mathrm{Ka})$ allele of Zic3 [56] and the TCF/Lef:H2B-GFP transgenic strain (MGI: 4881498, [63]) were maintained by continuous backcross to C57BL/6J inbred mice. Mice were maintained in a light cycle of $12 \mathrm{~h}$ light: $12 \mathrm{~h}$ dark, the midpoint of the dark cycle being 12 a.m.. Embryos were dissected from 49-150-day-old pregnant females. Mice and embryos were genotyped by PCR screening of genomic DNA extracted from ear biopsy tissue or embryonic tissue, respectively [69]. For the $\mathrm{Zic5}^{-}, \mathrm{Zic} 3^{\mathrm{Ka}}$, and TCF/Lef:H2B-GFP strains, genomic DNA (50 ng) was amplified for High-Resolution Melt Analysis (HRMA) using IMMOLASE DNA Polymerase using the primers and PCR conditions previously described: Zic5- $[25,70]$, $\mathrm{Zic}^{\mathrm{Ka}}[56,70]$, and TCF/Lef:H2B-GFP [63]. For the Zic2 ${ }^{K u}$ strain, genomic DNA (50 ng) was amplified for Allelic Discrimination using the primers and PCR conditions previously described [36].

\subsection{Embryo Collection and Pre-Processing}

All embryos were dissected from maternal tissue and Reichert's membrane removed in $10 \%(\mathrm{v} / \mathrm{v})$ fetal bovine serum in phosphate buffered saline (PBS) as described previously [71]. Embryos were staged according to Downs and Davies [72]. Embryos for whole mount in situ hybridization (WMISH) were transferred to $4 \%$ paraformaldehyde (PFA; Millipore Sigma, St. Louis, MO, USA: P6148) in 1X PBS and fixed overnight at $4{ }^{\circ} \mathrm{C}$, before being used immediately or dehydrated via a methanol series and stored in $100 \%$ methanol at $-20^{\circ} \mathrm{C}$ until required. Embryos for whole mount immunofluorescence (WMIF) were transferred to 4\% paraformaldehyde (PFA; Millipore Sigma: P6148) in 1X PBS and fixed overnight at $4{ }^{\circ} \mathrm{C}$, before being used immediately or stored in $1 \mathrm{X}$ PBS at $4{ }^{\circ} \mathrm{C}$.

\subsection{Whole Mount in Situ Hybridization}

Whole embryos were re-hydrated using standard procedures [71] and rinsed in PBT (PBS with 0.1\% Tween-20 [Millipore Sigma: P9416]). WMISH to Foxd3 was performed as previously described $[25,36,71,73]$. A minimum of four, eight somite-stage embryos per genotype were compared to precisely stage-matched, wild-type littermates. Upon 
completion of the WMISH procedure, embryos were postfixed in 4\% PFA and transferred via a glycerol series to $100 \%$ glycerol. For photography, embryos were flat-mounted under a glass coverslip and photographed in a Nikon SMZ 21500 Stereomicroscope and DS-Ri1 camera (Nikon Inc., Melville, NY, USA).

\subsection{Whole Mount Immunofluorescence and Confocal Microscopy}

Whole embryos were rinsed in PBT and permeabilized in $1 \% \mathrm{H}_{2} \mathrm{O}_{2}$ [Millipore Sigma: $\mathrm{H} 1009$ ] for $10 \mathrm{~min}$ at room temperature (RT) followed by $10 \mathrm{mg} / \mathrm{mL}$ proteinase $\mathrm{K}$ [Roche, Basel, Switzerland: 3115879001] in PBT for $5 \mathrm{~min}$, RT, and $2 \mathrm{mg} / \mathrm{mL}$ glycine in PBT for 5 min, RT. For GFP detection, embryos were blocked in 5\% skim milk powder (w/v; Diploma, New Zealand Dairy Products Bangladesh Ltd, Dhaka, Bangladesh: 3001742) in PBT at RT for a minimum of $3 \mathrm{~h}$, incubated overnight at $4{ }^{\circ} \mathrm{C}$ with $\alpha$-GFP (Abcam, Cambridge, UK; cat. no. ab6673; 1:100) primary antibody, blocked again in 5\% skim milk powder at RT for a minimum of $3 \mathrm{~h}$, and incubated for $48 \mathrm{~h}$ at $4{ }^{\circ} \mathrm{C}$ with a donkey $\alpha$-goat Alexa Fluor Plus 647 (ThermoFisher Scientific, Waltham, MA, USA; cat. no. A32849; 1:500) secondary antibody. Embryos were rinsed in 5\% skim milk powder followed by PBT at RT before incubation with DAPI $(0.005 \mathrm{mg} / \mathrm{mL}$ in PBS; ThermoFisher Scientific, cat. no. D3571; 1:1000) for $10 \mathrm{~min}$ at RT. Whole embryos were taken through a glycerol series [71] and mounted on SuperFrost Plus microscope slides or single-well cavity slides (ProSciTech, Kirwan, QLD, Australia: G341, $1.25 \mathrm{~mm}$ ) and imaged through glass coverslips.

Laser scanning confocal data of immunofluorescent embryos and cryosections were acquired using a Zeiss LSM800 with Airyscan Super-resolution confocal microscope with a 10X and 20X objectives (Zeiss, Oberkochen, Germany) and DIC optics. Fluorophores were excited using a 405-nm diode laser (Hoechst-33342; DAPI) or 633-nm HeNe laser (AlexaFluor-633/647). Confocal images were acquired using ZEN BLUE as $z$ stacks of $x y$ images taken at $3-\mu \mathrm{m} z$-intervals for whole embryos and $0.5-\mu \mathrm{m}$ for cryosections. A minimum of six embryos per genotype per stage were compared to precisely stage-matched, wild-type littermates. Maximum Intensity Projection 3D reconstructions of confocal zstacks were created for each embryo. Images were processed and prepared using Adobe Photoshop 2021 (Adobe, San Francisco, CA, USA).

Post-whole mount confocal microscopy, embryos to be cryosectioned were taken through a series of Tissue-Tek OCT (ProSciTech: IA018) cryoembedding solution dilutions in 30\% sucrose/PBS (1:3 OCT:30\% sucrose, 1:1 OCT:30\% sucrose, 3:1 OCT:30\% sucrose) before being embedded in molds in 100\% OCT and frozen on dry ice. OCT blocks were sectioned using ThermoFisher Scientific; HM525 NX Cryostat at 10-16 $\mu \mathrm{m}$ and the sections were adhered to SuperFrost Plus microscope slides (ThermoFisher Scientific: 4951PLUS4) coated in 2\% (3-Aminopropyl)triethoxysilane (Millipore Sigma: A3648) diluted in acetone to ensure section adherence. Slides were stored at $-20{ }^{\circ} \mathrm{C}$ and subjected to confocal microscopy as above.

\subsection{Plasmids}

The generation of pENTR3C-ZIC2-WT, pENTR3C-ZIC3-WT, pENTR3C-ZIC5-WT, V5-ZIC2, V5-ZIC3, V5-ZIC5, V5-DEST, and $\Delta$ N89- $\beta$-cat has been described previously [56], as has the generation of V5- $\beta$-catenin, pGL4.2- $\beta$-globin-Foxd3, EmGFP-SUMO-wt, EmGFPSUMO- $\triangle$ GG, pSG5-HA-hUBC9, and FLAG-UBC9-C93S [25]. The generation of pENTR3CZIC1, pENTR3C-ZIC4, V5-ZIC1-wt, and V5-ZIC4-wt has also been described previously [57].

The $3 \times$ optimal TCF binding sites (WNT response elements; WRE) or $3 \times$ mutant TCF binding sites (mutant WNT response elements; MRE) were inserted into KpnI/HindIII restriction binding sites of pGL4.2 to generate pGL4.2-WREx3 and pGL4.2-MREx3. The human $\beta$-globin minimal promoter was amplified from pGL4.2- $\beta$-globin and inserted into HindIII restriction enzyme site of pGL4.2-WREx3 and pGL4.2-MREx3 to generate pGL4.2- $\beta$-globin-WREx3 and pGL4.2- $\beta$-globin-MREx3.

Specific point mutations were introduced into pENTR3C-ZIC3 using the QuikChange II Site-Directed Mutagenesis kit (Agilent, Santa Clara, CA, USA) to generate pENTR3C- 
ZIC3K248R (using primers Ark1181_F 5' - ATGCGGCAGCCTATCAGGCAGGAGCTGTCG$3^{\prime}$ and Ark1182_R 5'-CGACAGCTCCTGCCTGATAGGCTGCCGCAT-3') and pENTR3CZIC3-K259R (using primers Ark1183_F 5'-GAGAAACCTTTCAGATGTGAATTTGAAGGC$3^{\prime}$ and Ark1181_R 5'- GCCTTCAAATTCACATCTGAAAGGTTTCTC-3'). Specific point mutations were introduced into pENTR3C-ZIC1 and pENTR3C-ZIC2 via overlap extension PCR to generate pENTR3C-ZIC1-K333R (using mutagenesis primers Ark1470_F 5'

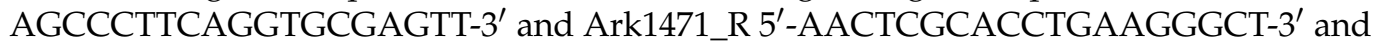
primers at the ends of ZIC1 Ark1460_F 5'-ATCCGGTACCGAATTCATGCTCCTGGACGCC GG-3' and ZIC1 Ark1461_R 5'-GTGCGGCCGCGAATTCTTAAACGTACCATTCGTTAAA ATTGG-3') and pENTR3C-ZIC2-K253R (using mutagenesis primers Ark1230_F 5'-CGGCAG CAGTGCATCAGGCAGGAGCTAATC-3' and Ark1231_R $5^{\prime}$-GATTAGCTCCTGCCTGATGC ACTGCTGCCG-3' and primers at the ends of ZIC2 Ark1168_F 5' - ATCCGGTACCGAATTCA GTGTGGTGGAATTCCTGGCC-3' ${ }^{\prime}$ and Ark1150_R 5'- GTGCGGCCGCGAATTCGAGGGT TAGGGATAGGCTTAC-3). To generate pENTR3C-ZIC1-K222R and pENTR3C-ZIC4-K125R, a 5' segment of each of pENTR3C-ZIC1 and pENTR3C-ZIC4 was amplified with primers containing the desired ZIC1-K222R and ZIC4-K125R mutations (using mutagenesis primer Ark1462_R 5'-GATGAGCTCTTGCCTGATGG-3' ${ }^{\prime}$ and wild-type end primer Ark1463_F 5' ATCCGGTACCGAATTCATG- $3^{\prime}$ in the case of ZIC1-K222R and using mutagenesis primer Ark1428_R 5'-ATGAGCTCCTGTCTGATGG-3' and wild-type end primer Ark1463_F 5'ATCCGGTACCGAATTCATG-3' in the case of ZIC4-K125R). These fragments were inserted into KpnI/SacI restriction sites of pENTR3C-ZIC1 and pENTR3C-ZIC4 to create pENTR3CZIC1K222R and pENTR3C-ZIC4K125R.

For all pENTR3C-ZIC constructs, UBC9 fusion constructs were generated by PCR amplifying UBC9 cDNA (with stop codon deleted) from pSG5-HA-hUBC9 [74] and inserting the resulting fragment into the KpnI restriction enzyme site at the N-terminus of each ZIC to create the various pENTR3C-UBC9-ZIC fusion constructs. For both the pENTR3C-ZIC constructs and the pENTR3C-UBC9-ZIC constructs, the ZIC sequence was transferred to the destination clone pcDNA3.1/nV5-DEST ${ }^{\mathrm{TM}}$ (ThermoFisher Scientific) via a Gateway ${ }^{\circledR} \mathrm{LR}$ Clonase reaction (as per manufacturer's instructions; ThermoFisher Scientific) to produce the V5-ZIC and V5-UBC9-ZIC expression plasmids.

\subsection{Cell Culture, Subcellular Fractionation, SDS-PAGE, and Western Blotting}

The human embryonic kidney cell line (HEK293T) was cultured and transiently transfected as previously described [56]. Subcellular fractionation, SDS-PAGE, and WB were performed as described in [25].

\subsection{SUMOylation Assays}

For the UFDS experiments, HEK293T cells grown in six-well TC plates (approximately $1 \times 10^{6}$ cells, Corning ${ }^{\circledR}$, Corning NY, USA; Cat. no. CLS3516) were transfected with $2 \mu \mathrm{g}$ ZIC with or without co-transfection of $2 \mu \mathrm{g}$ of an EmGFP-SUMO expression construct. For non-UFDS experiments, $12 \mu \mathrm{g}$ ZIC with or without co-transfection of $12 \mu \mathrm{g}$ of an EmGFP-SUMO expression construct cells were grown in 100-mm TC dishes (approximately $7 \times 10^{6}$ cells, Corning ${ }^{\circledR}$; Cat. no. CLS430167). For experiments not including BIO $\left(\left(2^{\prime} \mathrm{Z}, 3^{\prime} \mathrm{E}\right)-6\right.$-Bromoindirubin-3'-oxime) treatment, $24 \mathrm{~h}$ after transfection, cells were lysed and analyzed via WB. For experiments including BIO treatment, $6 \mathrm{~h}$ after transfection, cells were dissociated from the growth surface using $0.05 \mathrm{~g} / \mathrm{L}$ trypsin and replated into two 100-mm TC dishes. Then, $24 \mathrm{~h}$ after transfection, media was removed and replaced with either media including both $5 \mu \mathrm{M}$ BIO and $0.5 \%$ DMSO or media with only the $0.5 \%$ DMSO. Then, $24 \mathrm{~h}$ after transfection, the cells were lysed and analyzed by WB. The relative amounts of SUMOylated ZIC with and without BIO treatment were quantified from scans of the resulting WBs using ImageJ (NIH). 


\subsection{Luciferase Reporter Assays}

Luciferase assays were performed as described previously [25,56], but with different initial transfection conditions. For the ZIC2 and ZIC3 Foxd3 reporter assays, HEK293T cells grown in 12-well plates were transfected with a total of $2 \mu \mathrm{g}$ of DNA, comprised of $0.8 \mu \mathrm{g}$ Foxd3 reporter, $0.8 \mu \mathrm{g}$ of either a ZIC expression construct or the empty construct (pcDNA3.1/nV5-DEST ${ }^{\mathrm{TM}}$ ), and $0.4 \mu \mathrm{g}$ of either the empty construct (pcDNA3.1/nV5DEST $^{\mathrm{TM}}$ ) or the dominant negative SUMOylation inhibitor FLAG-UBC9-C93S. For the ZIC1 and ZIC4 Foxd3 reporter assays, HEK293T cells grown in 12-well plates were transfected with a total of $1.6 \mu \mathrm{g}$ of DNA, comprised of $0.8 \mu \mathrm{g}$ Foxd3 reporter and $0.8 \mu \mathrm{g}$ of either a ZIC expression construct or the empty construct (pcDNA3.1/nV5-DEST ${ }^{\mathrm{TM}}$ ). For the Z3M2 reporter assays, HEK293T cells grown in 12-well plates were transfected with a total of $2 \mu \mathrm{g}$ of DNA, comprised of $0.8 \mu \mathrm{g} Z 3 M 2$ reporter, $0.8 \mu \mathrm{g}$ of either a ZIC expression construct or the empty construct (pcDNA3.1/nV5-DEST ${ }^{\mathrm{TM}}$ ), and $0.4 \mu \mathrm{g}$ of either the empty construct (pcDNA3.1/nV5-DEST ${ }^{\mathrm{TM}}$ ) or the dominant negative SUMOylation inhibitor FLAG-UBC9-C93S. For the WNT inhibition assays, HEK293T cells grown in six-well plates were transfected with a total of $4.5 \mu \mathrm{g}$ of DNA, comprised of $1.5 \mu \mathrm{g}$ pGL4.2- $\beta$-globin-TCFx3 reporter, $1.5 \mu \mathrm{g} \beta$-catenin expression construct (either V5- $\beta$-catenin or $\Delta$ N89- $\beta$-catenin), $1 \mu \mathrm{g}$ of either a ZIC expression construct or the empty construct (pcDNA3.1/nV5-DEST ${ }^{\mathrm{TM}}$ ), and $0.5 \mu \mathrm{g}$ of either the empty construct (pcDNA3.1/nV5-DEST ${ }^{\mathrm{TM}}$ ) or the dominant negative SUMOylation inhibitor FLAG-UBC9-C93S. In addition, to assess WNT background levels, for one well the $\beta$-catenin expression construct was substituted with the empty construct (pcDNA3.1/nV5-DEST ${ }^{\mathrm{TM}}$ ).

\subsection{Antibodies}

The following primary antibodies were used for WBs: mouse monoclonal anti-V5 (1:5000 dilution WB, ThermoFisher Scientific, cat. no. R960-25), rabbit polyclonal anti-GFP (1:1500 dilution WB, Cell Signaling, Danvers, MA, USA; cat. no. 2555), rabbit polyclonal anti-Lamin B1 (1:1500 dilution WB, Abcam, cat. no. ab16048), mouse monoclonal anti$\beta$-tubulin (1:1000 dilution WB, Abcam, cat. no. ab7792), mouse monoclonal anti-TATA Binding Protein (TBP) (1:2000 dilution WB, Abcam, cat. no. ab818), goat polyclonal $\beta$ catenin C-18 (1:500 dilution WB, Santa Cruz Biotechnology, Dallas, TX, USA; cat. no. sc-1496), and mouse monoclonal anti-UBC9 (1:1000 dilution WB, BD Biosciences, Franklin Lakes, NJ, USA; cat no. 610748). Secondary antibodies used for WB (1:5000 dilution) were: horse radish peroxidase (HRP)-conjugated rabbit anti-mouse, rabbit anti-goat, and goat anti-rabbit (Zymed, ThermoFisher Scientific). All antibodies were diluted in blocking buffer (5\% skim milk [Diploma], 0.02\% Tween-20 in PBS except for the GFP antibody, for which the PBS was replaced with TBS [Tris-Buffered Saline; $50 \mathrm{mM}$ Tris, $150 \mathrm{mM} \mathrm{NaCl}$, $\mathrm{pH} 7.5])$.

\subsection{Statistical Analysis}

For cell-based assays where one representative experiment is shown, the standard deviation was calculated from three internal repeats using Excel. For analysis of the pooled raw data (from a minimum of three external repeats) of these assays, GenStat software (VSN International, Hemel Hempstead, UK) was used to test for normality (W-test) and to perform a two-way ANOVA and Bonferroni multiple comparison test. Post-statistical analysis, the values calculated by the ANOVA and the SEM were normalized to the negative control and relative values plotted.

For statistical analysis of the amount of SUMOylated ZIC in response to BIO treatment, GenStat software was used to perform a paired two-sample $t$-test on data from three independent repeats. Post-analysis, predicted means and standard error of difference (SED) were plotted. 
Supplementary Materials: The following are available online at https: / www.mdpi.com/article/ 10.3390/ijms221910437/s1. Figure S1: ZIC1-4 proteins are SUMOylated in HEK293T cells. Figure S2: The UFDS system confirms the ZF-NC domain as the sole site of SUMO attachment for ZIC1-4 proteins. Figure S3: SUMOylation does not alter ZIC1 or ZIC4 activation of the Foxd3 enhancer. Figure S4: A ZIC-optimized, TCF-dependent transcription assay. Figure S5: SUMOylation reduces ZIC1 but not ZIC4 inhibition of WNT signaling.

Author Contributions: Conceptualization: R.M.A.; Methodology: H.M.B., K.S.B., and R.M.A.; Validation: H.M.B., K.S.B., K.E.M.D., and R.M.A.; Formal analysis: H.M.B., K.S.B., K.E.M.D., and R.M.A.; Investigation: H.M.B., K.S.B., K.E.M.D., and R.M.A.; Resources: R.M.A.; Data curation: H.M.B., K.S.B., and K.E.M.D.; Writing—original draft: H.M.B., K.S.B., K.E.M.D., and R.M.A.; Writing—review and editing: H.M.B., K.S.B., K.E.M.D., and R.M.A.; Visualization: H.M.B., K.S.B., and K.E.M.D.; Supervision: R.M.A.; Project administration: R.M.A.; Funding acquisition: R.M.A. All authors have read and agreed to the published version of the manuscript.

Funding: This work was supported by the award of a Sylvia and Charles Viertel Senior Medical Fellowship to R.M.A.

Institutional Review Board Statement: The study was conducted according to the Australian Standards for Animal Care under protocol A2018/36 approved by The Australian National University Animal Ethics and Experimentation Committee.

Data Availability Statement: The data presented in this study are available on request from the corresponding author.

Conflicts of Interest: The authors declare no conflict of interest.

\section{References}

1. Le Douarin, N.M.; Dupin, E. The Neural Crest, a Fourth Germ Layer of the Vertebrate Embryo: Significance in Chordate Evolution. In Neural Crest Cells: Evolution, Development and Disease; Elsevier Inc.: Amsterdam, The Netherlands, 2014; pp. 3-26. ISBN 9780124017306.

2. Simões-Costa, M.; Bronner, M.E. Establishing neural crest identity: A gene regulatory recipe. Development 2015, 142, 242-257. [CrossRef]

3. Stuhlmiller, T.J.; García-Castro, M.I. Current perspectives of the signaling pathways directing neural crest induction. Cell. Mol. Life Sci. 2012, 69, 3715-3737. [CrossRef]

4. Groves, A.K.; LaBonne, C. Setting appropriate boundaries: Fate, patterning and competence at the neural plate border. Dev. Biol. 2014, 389, 2-12. [CrossRef] [PubMed]

5. Barriga, E.H.; Trainor, P.A.; Bronner, M.; Mayor, R. Animal models for studying neural crest development: Is the mouse different? Development 2015, 142, 1555-1560. [CrossRef] [PubMed]

6. Saint-Jeannet, J.P.; He, X.; Varmus, H.E.; Dawid, I.B. Regulation of dorsal fate in the neuraxis by Wnt-1 and Wnt-3a. Proc. Natl. Acad. Sci. USA 1997, 94, 13713-13718. [CrossRef] [PubMed]

7. García-Castro, M.I.; Marcelle, C.; Bronner-Fraser, M. Ectodermal Wnt function as a neural crest inducer. Science 2002, $297,848-851$. [CrossRef]

8. Elkouby, Y.M.; Elias, S.; Casey, E.S.; Blythe, S.A.; Tsabar, N.; Klein, P.S.; Root, H.; Liu, K.J.; Frank, D. Mesodermal Wnt signaling organizes the neural plate via Meis3. Development 2010, 137, 1531-1541. [CrossRef]

9. Sun, X.; Zhang, R.; Lin, X.; Xu, X. Wnt3a regulates the development of cardiac neural crest cells by modulating expression of cysteine-rich intestinal protein 2 in rhombomere 6. Circ. Res. 2008, 102, 831-839. [CrossRef]

10. LaBonne, C.; Bronner-Fraser, M. Neural crest induction in Xenopus: Evidence for a two signal model. Development 1998, 125, 2403-2414. [CrossRef]

11. Steventon, B.; Araya, C.; Linker, C.; Kuriyama, S.; Mayor, R. Differential requirements of BMP and Wnt signalling during gastrulation and neurulation define two steps in neural crest induction. Development 2009, 136, 771-779. [CrossRef] [PubMed]

12. Lewis, J.L.; Bonner, J.; Modrell, M.; Ragland, J.W.; Moon, R.T.; Dorsky, R.I.; Raible, D.W. Reiterated Wnt signaling during zebrafish neural crest development. Development 2004, 131, 1299-1308. [CrossRef] [PubMed]

13. Van Amerongen, R.; Berns, A. Knockout mouse models to study Wnt signal transduction. Trends Genet. 2006, 22, 678-689. [CrossRef] [PubMed]

14. Takada, S.; Stark, K.L.; Shea, M.J.; Vassileva, G.; McMahon, J.A.; McMahon, A.P. Wnt-3a regulates somite and tailbud formation in the mouse embryo. Genes Dev. 1994, 8, 174-189. [CrossRef] [PubMed]

15. Greco, T.L.; Takada, S.; Newhouse, M.M.; McMahon, J.A.; McMahon, A.P.; Camper, S.A. Analysis of the vestigial tail mutation demonstrates that Wnt-3a gene dosage regulates mouse axial development. Genes Dev. 1996, 10, 313-324. [CrossRef]

16. Yoshikawa, Y.; Fujimori, T.; McMahon, A.P.; Takada, S. Evidence that absence of Wnt-3a signaling promotes neuralization instead of paraxial mesoderm development in the mouse. Dev. Biol. 1997, 183, 234-242. [CrossRef] 
17. Nakaya, M.A.; Biris, K.; Tsukiyama, T.; Jaime, S.; Rawls, J.A.; Yamaguchi, T.P. Wnt3a links left-right determination with segmentation and anteroposterior axis elongation. Development 2005, 132, 5425-5436. [CrossRef]

18. Lee, S.M.K.; Tole, S.; Grove, E.; McMahon, A.P. A local Wnt-3a signal is required for development of the mammalian hippocampus. Development 2000, 127, 457-467. [CrossRef]

19. Carmona-Fontaine, C.; Acuña, G.; Ellwanger, K.; Niehrs, C.; Mayor, R. Neural crests are actively precluded from the anterior neural fold by a novel inhibitory mechanism dependent on Dickkopf1 secreted by the prechordal mesoderm. Dev. Biol. 2007, 309, 208-221. [CrossRef]

20. Mašek, J.; Machoň, O.; Kořínek, V.; Taketo, M.M.; Kozmik, Z. Tcf7l1 protects the anterior neural fold from adopting the neural crest fate. Development 2016, 143, 2206-2216. [CrossRef]

21. Luan, Z.; Liu, Y.; Stuhlmiller, T.J.; Marquez, J.; García-Castro, M.I. SUMOylation of Pax7 is essential for neural crest and muscle development. Cell. Mol. Life Sci. 2013, 70, 1793-1806. [CrossRef]

22. Taylor, K.M.; LaBonne, C. SoxE factors function equivalently during neural crest and inner ear development and their activity is regulated by SUMOylation. Dev. Cell 2005, 9, 593-603. [CrossRef] [PubMed]

23. Liu, J.A.J.; Wu, M.H.; Yan, C.H.; Chau, B.K.H.; So, H.; Ng, A.; Chan, A.; Cheah, K.S.E.; Briscoe, J.; Cheung, M. Phosphorylation of Sox9 is required for neural crest delamination and is regulated downstream of BMP and canonical Wnt signaling. Proc. Natl. Acad. Sci. USA 2013, 110, 2882-2887. [CrossRef] [PubMed]

24. Lee, P.C.; Taylor-Jaffe, K.M.; Nordin, K.M.; Prasad, M.S.; Lander, R.M.; LaBonne, C. SUMOylated SoxE factors recruit Grg4 and function as transcriptional repressors in the neural crest. J. Cell Biol. 2012, 198, 799-813. [CrossRef]

25. Ali, R.G.; Bellchambers, H.M.; Warr, N.; Ahmed, J.N.; Barratt, K.S.; Neill, K.; Diamand, K.E.M.; Arkell, R.M. WNT responsive SUMOylation of ZIC5 promotes murine neural crest cell development via multiple effects on transcription. J. Cell Sci. 2021, 134, jcs.256792. [CrossRef]

26. Milet, C.; Maczkowiak, F.; Roche, D.D.; Monsoro-Burq, A.H. Pax3 and Zic1 drive induction and differentiation of multipotent, migratory, and functional neural crest in Xenopus embryos. Proc. Natl. Acad. Sci. USA 2013, 110, 5528-5533. [CrossRef] [PubMed]

27. Plouhinec, J.L.; Roche, D.D.; Pegoraro, C.; Figueiredo, A.L.; Maczkowiak, F.; Brunet, L.J.; Milet, C.; Vert, J.P.; Pollet, N.; Harland, R.M.; et al. Pax3 and Zic1 trigger the early neural crest gene regulatory network by the direct activation of multiple key neural crest specifiers. Dev. Biol. 2014, 386, 461-472. [CrossRef] [PubMed]

28. Sato, T.; Sasai, N.; Sasai, Y. Neural crest determination by co-activation of Pax3 and Zic1 genes in Xenopus ectoderm. Development 2005, 132, 2355-2363. [CrossRef]

29. Simões-Costa, M.S.; McKeown, S.J.; Tan-Cabugao, J.; Sauka-Spengler, T.; Bronner, M.E. Dynamic and Differential Regulation of Stem Cell Factor FoxD3 in the Neural Crest Is Encrypted in the Genome. PLoS Genet. 2012, 8, e1003142. [CrossRef]

30. Elms, P.; Scurry, A.; Davies, J.; Willoughby, C.; Hacker, T.; Bogani, D.; Arkell, R.M. Overlapping and distinct expression domains of Zic2 and Zic3 during mouse gastrulation. Gene Expr. Patterns 2004, 4, 505-511. [CrossRef]

31. Diamand, K.E.M.; Barratt, K.S.; Arkell, R.M. Overview of Rodent Zic Genes; Springer: Singapore, 2018; Volume 1046.

32. Furushima, K.; Murata, T.; Matsuo, I.; Aizawa, S. A new murine zinc finger gene, Opr. Mech. Dev. 2000, 98, 161-164. [CrossRef]

33. Nagai, T.; Aruga, J.; Takada, S.; Günther, T.; Spörle, R.; Schughart, K.; Mikoshiba, K. The expression of the mouse Zic1, Zic2, and Zic3 gene suggests an essential role for Zic genes in body pattern formation. Dev. Biol. 1997, 182, 299-313. [CrossRef]

34. Houtmeyers, R.; Souopgui, J.; Tejpar, S.; Arkell, R.M. The ZIC gene family encodes multi-functional proteins essential for patterning and morphogenesis. Cell. Mol. Life Sci. 2013, 70, 3791-3811. [CrossRef]

35. Inoue, T.; Hatayama, M.; Tohmonda, T.; Itohara, S.; Aruga, J.; Mikoshiba, K. Mouse Zic5 deficiency results in neural tube defects and hypoplasia of cephalic neural crest derivatives. Dev. Biol. 2004, 270, 146-162. [CrossRef]

36. Elms, P.; Siggers, P.; Napper, D.; Greenfield, A.; Arkell, R.M. Zic2 is required for neural crest formation and hindbrain patterning during mouse development. Dev. Biol. 2003, 264, 391-406. [CrossRef] [PubMed]

37. Nagai, T.; Aruga, J.; Minowa, O.; Sugimoto, T.; Ohno, Y.; Noda, T.; Mikoshiba, K. Zic2 regulates the kinetics of neurulation. Proc. Natl. Acad. Sci. USA 2000, 97, 1618-1623. [CrossRef]

38. Furushima, K.; Murata, T.; Kiyonari, H.; Aizawa, S. Characterization of Opr deficiency in mouse brain: Subtle defects in dorsomedial telencephalon and medioventral forebrain. Dev. Dyn. 2005, 232, 1056-1061. [CrossRef]

39. Badis, G.; Berger, M.F.; Philippakis, A.A.; Talukder, S.; Gehrke, A.R.; Jaeger, S.A.; Chan, E.T.; Metzler, G.; Vedenko, A.; Chen, X.; et al. Diversity and complexity in DNA recognition by transcription factors. Science 2009, 324, 1720-1723. [CrossRef] [PubMed]

40. Lim, L.S.; Hong, F.H.; Kunarso, G.; Stanton, L.W. The pluripotency regulator Zic3 is a direct activator of the Nanog promoter in ESCs. Stem Cells 2010, 28, 1961-1969. [CrossRef]

41. Koyabu, Y.; Nakata, K.; Mizugishi, K.; Aruga, J.; Mikoshiba, K. Physical and functional interactions between Zic and Gli proteins. J. Biol. Chem. 2001, 276, 6889-6892. [CrossRef]

42. Pourebrahim, R.; Houtmeyers, R.; Ghogomu, S.; Janssens, S.; Thelie, A.; Tran, H.T.; Langenberg, T.; Vleminckx, K.; Bellefroid, E.; Cassiman, J.J.; et al. Transcription factor Zic2 inhibits Wnt/Beta-catenin protein signaling. J. Biol. Chem. 2011, 286, 37732-37740. [CrossRef] [PubMed]

43. Bedard, J.E.J.; Purnell, J.D.; Ware, S.M. Nuclear import and export signals are essential for proper cellular trafficking and function of ZIC3. Hum. Mol. Genet. 2007, 16, 187-198. [CrossRef] 
44. Hatayama, M.; Tomizawa, T.; Sakai-Kato, K.; Bouvagnet, P.; Kose, S.; Imamoto, N.; Yokoyama, S.; Utsunomiya-Tate, N.; Mikoshiba, K.; Kigawa, T.; et al. Functional and structural basis of the nuclear localization signal in the ZIC3 zinc finger domain. Hum. Mol. Genet. 2008, 17, 3459-3473. [CrossRef]

45. Ramakrishnan, A.B.; Sinha, A.; Fan, V.B.; Cadigan, K.M. The Wnt Transcriptional Switch: TLE Removal or Inactivation? BioEssays 2018, 40, 1700162. [CrossRef] [PubMed]

46. Fujimi, T.J.; Hatayama, M.; Aruga, J. Xenopus Zic3 controls notochord and organizer development through suppression of the Wnt/ $\beta$-catenin signaling pathway. Dev. Biol. 2012, 361, 220-231. [CrossRef] [PubMed]

47. Zhao, Z.; Wang, L.; Bartom, E.; Marshall, S.; Rendleman, E.; Ryan, C.; Shilati, A.; Savas, J.; Chandel, N.; Shilatifard, A. $\beta-$ Catenin/Tcf712-dependent transcriptional regulation of GLUT1 gene expression by Zic family proteins in colon cancer. Sci. Adv. 2019, 5, 1-14. [CrossRef]

48. Aruga, J.; Kamiya, A.; Takahashi, H.; Fujimi, T.J.; Shimizu, Y.; Ohkawa, K.; Yazawa, S.; Umesono, Y.; Noguchi, H.; Shimizu, T.; et al. A wide-range phylogenetic analysis of Zic proteins: Implications for correlations between protein structure conservation and body plan complexity. Genomics 2006, 87, 783-792. [CrossRef] [PubMed]

49. Chen, L.; Ma, Y.; Qian, L.; Wang, J. Sumoylation regulates nuclear localization and function of zinc finger transcription factor ZIC3. Biochim. Biophys. Acta-Mol. Cell Res. 2013, 1833, 2725-2733. [CrossRef]

50. Hendriks, I.A.; Vertegaal, A.C.O. A comprehensive compilation of SUMO proteomics. Nat. Rev. Mol. Cell Biol. 2016, 17, 581-595. [CrossRef]

51. Gareau, J.R.; Lima, C.D. The SUMO pathway: Emerging mechanisms that shape specificity, conjugation and recognition. Nat. Rev. Mol. Cell Biol. 2010, 11, 861-871. [CrossRef]

52. Jakobs, A.; Koehnke, J.; Himstedt, F.; Funk, M.; Korn, B.; Gaestel, M.; Niedenthal, R. Ubc9 fusion-directed SUMOylation (UFDS): A method to analyze function of protein SUMOylation. Nat. Methods 2007, 4, 245-250. [CrossRef]

53. Jakobs, A.; Himstedt, F.; Funk, M.; Korn, B.; Gaestel, M.; Niedenthal, R. Ubc9 fusion-directed SUMOylation identifies constitutive and inducible SUMOylation. Nucleic Acids Res. 2007, 35, e109. [CrossRef] [PubMed]

54. Kamitani, T.; Nguyen, H.P.; Yeh, E.T.H. Preferential modification of nuclear proteins by a novel ubiquitin-like molecule. J. Biol. Chem. 1997, 272, 14001-14004. [CrossRef]

55. Bogani, D.; Warr, N.; Elms, P.; Davies, J.; Tymowska-Lalanne, Z.; Goldsworthy, M.; Cox, R.D.; Keays, D.A.; Flint, J.; Wilson, V.; et al. New semidominant mutations that affect mouse development. Genesis 2004, 40, 109-117. [CrossRef] [PubMed]

56. Ahmed, J.N.; Ali, R.G.; Warr, N.N.; Wilson, H.M.; Bellchambers, H.M.; Barratt, K.S.; Thompson, J.; Arkell, R.M. A murine Zic3 transcript with a premature termination codon evades nonsense-mediated decay during axis formation. Dis. Model. Mech. 2013, 6, 755-767. [CrossRef]

57. Ahmed, J.N.; Diamand, K.E.M.; Bellchambers, H.M.; Arkell, R.M. Systematized reporter assays reveal ZIC protein regulatory abilities are Subclass-specific and dependent upon transcription factor binding site context. Sci. Rep. 2020, 10, 13130. [CrossRef]

58. Poukka, H.; Aarnisalo, P.; Karvonen, U.; Palvimo, J.J.; Jänne, O.A. Ubc9 interacts with the androgen receptor and activates receptor- dependent transcription. J. Biol. Chem. 1999, 274, 19441-19446. [CrossRef] [PubMed]

59. Mizugishi, K.; Aruga, J.; Nakata, K.; Mikoshiba, K. Molecular properties of Zic proteins as transcriptional regulators and their relationship to GLI proteins. J. Biol. Chem. 2001, 276, 2180-2188. [CrossRef]

60. Ishiguro, A.; Inoue, T.; Mikoshiba, K.; Aruga, J. Molecular properties of Zic4 and Zic5 proteins: Functional diversity within Zic family. Biochem. Biophys. Res. Commun. 2004, 324, 302-307. [CrossRef] [PubMed]

61. Brown, L.Y.; Paraso, M.; Arkell, R.M.; Brown, S. In vitro analysis of partial loss-of-function ZIC2 mutations in holoprosencephaly: Alanine tract expansion modulates DNA binding and transactivation. Hum. Mol. Genet. 2005, 14, 411-420. [CrossRef]

62. Munemitsu, S.; Albert, I.; Rubinfeld, B.; Polakis, P. Deletion of an amino-terminal sequence beta-catenin in vivo and promotes hyperphosporylation of the adenomatous polyposis coli tumor suppressor protein. Mol. Cell. Biol. 1996, 16, 4088-4094. [CrossRef]

63. Ferrer-Vaquer, A.; Piliszek, A.; Tian, G.; Aho, R.J.; Dufort, D.; Hadjantonakis, A.K. A sensitive and bright single-cell resolution live imaging reporter of Wnt/ss-catenin signaling in the mouse. BMC Dev. Biol. 2010, 10, 121. [CrossRef] [PubMed]

64. Ewan, K.; Stubbs, M.; Todd, H.; Barbeau, O.; Botfield, H.; Young, R.; Ruddle, R.; Samuel, L.; Raynaud, F.; Allen, N.; et al. A Useful Approach To Identify Novel Small Molecule Inhibitors Of Wnt-Dependent Transcription. Cancer Res. 2011, 70, 5963-5973. [CrossRef] [PubMed]

65. Costa, M.W.; Lee, S.; Furtado, M.B.; Xin, L.; Sparrow, D.B.; Martinez, C.G.; Dunwoodie, S.L.; Kurtenbach, E.; Mohun, T.; Rosenthal, N.; et al. Complex SUMO-1 Regulation of Cardiac Transcription Factor Nkx2-5. PLoS ONE 2011, 6, e24812. [CrossRef]

66. Inoue, T.; Ota, M.; Mikoshiba, K.; Aruga, J. Zic2 and Zic3 synergistically control neurulation and segmentation of paraxial mesoderm in mouse embryo. Dev. Biol. 2007, 306, 669-684. [CrossRef]

67. Kimura-Yoshida, C.; Mochida, K.; Ellwanger, K.; Niehrs, C.; Matsuo, I. Fate Specification of Neural Plate Border by Canonical Wnt Signaling and Grhl3 is Crucial for Neural Tube Closure. EBioMedicine 2015, 2, 513-527. [CrossRef]

68. Nolan, P.M.; Peters, J.; Strivens, M.; Rogers, D.; Hagan, J.; Spurr, N.; Gray, I.C.; Vizor, L.; Brooker, D.; Whitehill, E.; et al. A systematic, genome-wide, phenotype-driven mutagenesis programme for gene function studies in the mouse. Nat. Genet. 2000, 25, 440-443. [CrossRef] [PubMed]

69. Arkell, R.M.; Cadman, M.; Marsland, T.; Southwell, A.; Thaung, C.; Davies, J.R.; Clay, T.; Beechey, C.V.; Evans, E.P.; Strivens, M.A.; et al. Genetic, physical, and phenotypic characterization of the Del(13)Svea36H mouse. Mamm. Genome 2001, 12, 687-694. [CrossRef] [PubMed] 
70. Thomsen, N.; Ali, R.G.; Ahmed, J.N.; Arkell, R.M.; Voelkerding, K. High Resolution Melt Analysis (HRMA); a Viable Alternative to Agarose Gel Electrophoresis for Mouse Genotyping. PLoS ONE 2012, 7, e45252. [CrossRef]

71. Barratt, K.S.; Arkell, R.M. Whole-Mount In Situ Hybridization in Post-Implantation Staged Mouse Embryos. Curr. Protoc. Mouse Biol. 2020, 10, e75. [CrossRef]

72. Downs, K.M.; Davies, T. Staging of gastrulating mouse embryos by morphological landmarks in the dissecting microscope. Development 1993, 118, 1255-1266. [CrossRef]

73. Barratt, K.S.; Arkell, R.M. Production of Digoxigenin-Labeled Riboprobes for In Situ Hybridization Experiments. Curr. Protoc. Mouse Biol. 2020, 10, e74. [CrossRef] [PubMed]

74. Chang, Y.L.; Huang, C.J.; Chan, J.Y.H.; Liu, P.Y.; Chang, H.P.; Huang, S.M. Regulation of nuclear receptor and coactivator functions by the carboxyl terminus of ubiquitin-conjugating enzyme 9. Int. J. Biochem. Cell Biol. 2007, 39, 1035-1046. [CrossRef] [PubMed] 